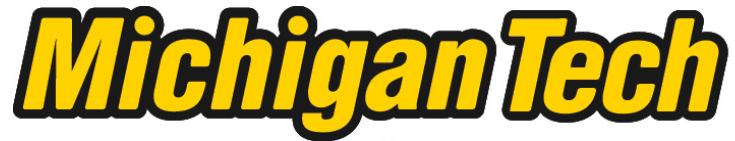 \\ Michigan Technological University Create the Future Digital Commons @ Michigan Tech
}

2013

\section{MODELING AND HARDWARE-IN-THE-LOOP SIMULATION OF POWER-SPLIT HYBRID ELECTRIC VEHICLES}

Shreyash Joshi

Michigan Technological University

Follow this and additional works at: https://digitalcommons.mtu.edu/etds

Part of the Mechanical Engineering Commons

Copyright 2013 Shreyash Joshi

\section{Recommended Citation}

Joshi, Shreyash, "MODELING AND HARDWARE-IN-THE-LOOP SIMULATION OF POWER-SPLIT HYBRID ELECTRIC VEHICLES", Master's report, Michigan Technological University, 2013.

https://doi.org/10.37099/mtu.dc.etds/824

Follow this and additional works at: https://digitalcommons.mtu.edu/etds

Part of the Mechanical Engineering Commons 
MODELING AND HARDWARE-IN-THE-LOOP SIMULATION OF POWER-SPLIT HYBRID ELECTRIC VEHICLES

By

Shreyash Joshi

\begin{abstract}
A REPORT
Submitted in partial fulfillment of the requirements for the degree of MASTER OF SCIENCE

In Mechanical Engineering
\end{abstract}

MICHIGAN TECHNOLOGICAL UNIVERSITY

2013

(C) 2013 Shreyash Joshi 
This report has been approved in partial fulfillment of the requirements for the Degree of MASTER OF SCIENCE in Mechanical Engineering.

Department of Mechanical Engineering-Engineering Mechanics

\author{
Report Advisor: $\quad$ Dr. Bo Chen
}

Committee Member: $\quad$ Dr. John Beard

Committee Member: Dr. Zhuo Feng

Department Chair: Dr. William W. Predebon 


\section{TABLE OF CONTENTS}

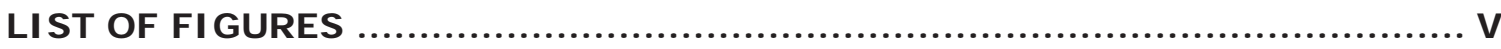

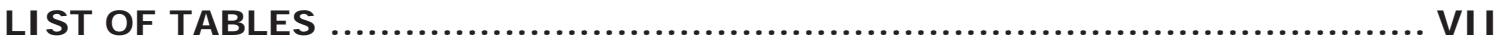

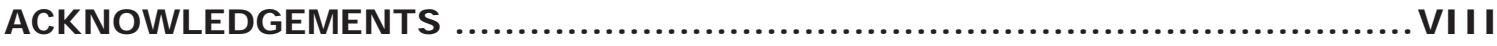

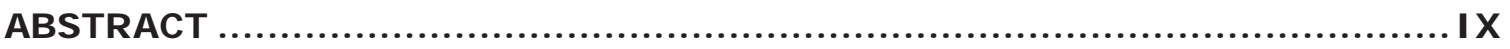

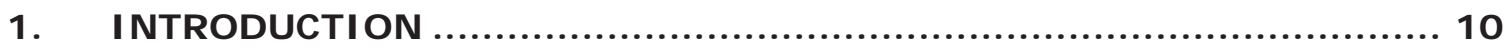

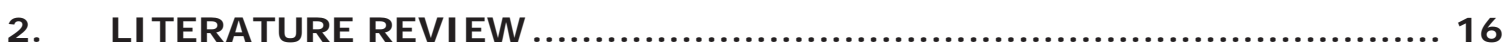

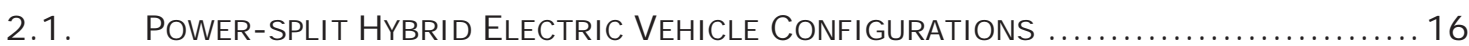

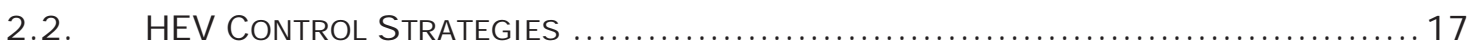

3. DYNAMI C MODEL OF POWER-SPLI T HEV POWERTRAI N ................... 18

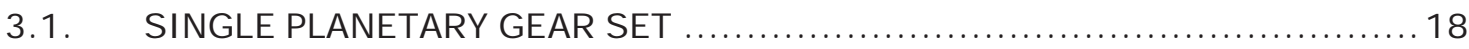

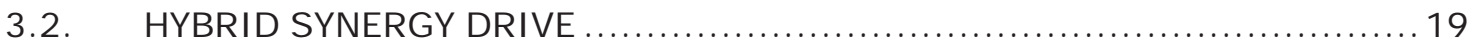

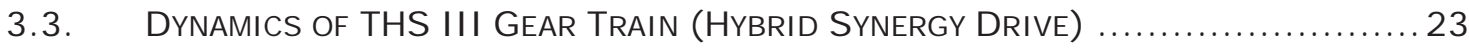

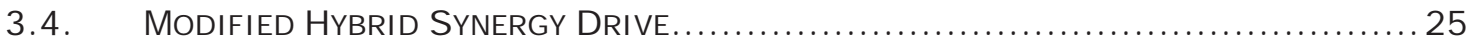

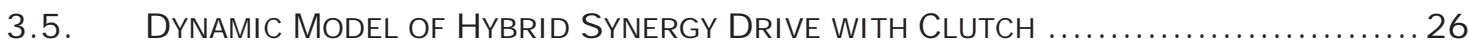

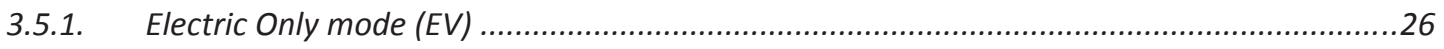

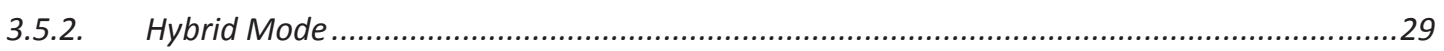

4. HI L SI MULATI ON VEHI CLE MODEL............................................... 33

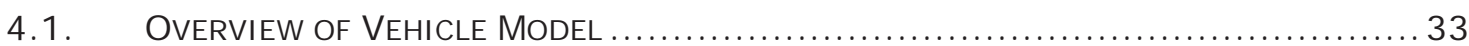

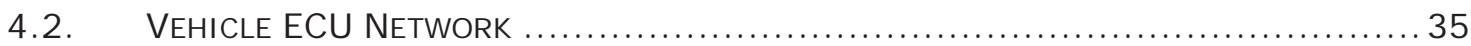

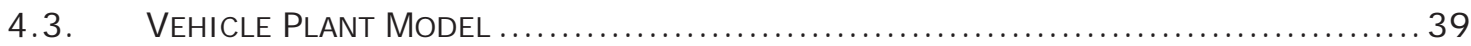

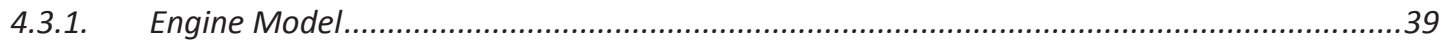

4.3.2. Model of Electronic Components......................................................................................40

4.3.3. Development of Power-split Drivetrain Model .......................................................45

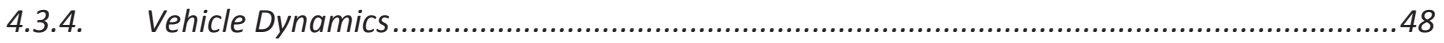

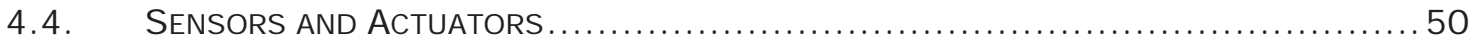

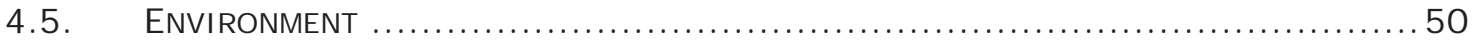

5. HI L SI MULATI ON AND RESULT DI SCUSSI ON ................................. 51

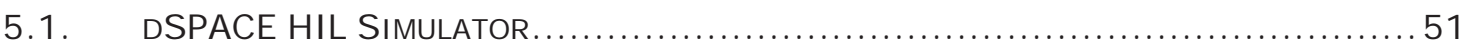




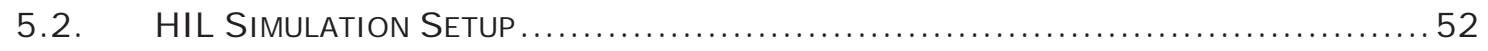

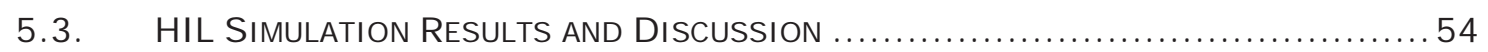

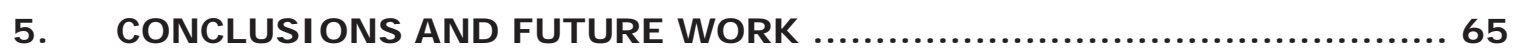

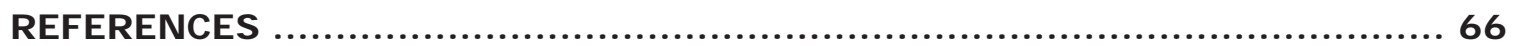




\section{LIST OF FI GURES}

FIGURE 1.1: PROJ ECTED DEMAND AND SUPPLY OF OIL RESERVES [1]. ............ 10

FIGURE 1.2: $\mathrm{CO}_{2}$ EMISSIONS FROM VARIOUS SOURCES [2] $\ldots \ldots \ldots \ldots \ldots \ldots \ldots \ldots \ldots \ldots \ldots \ldots \ldots \ldots \ldots$

FIGURE 1.3: CHANGE IN TEMPERATURE SINCE INTRODUCTION OF ICE [1] $\ldots \ldots \ldots \ldots 12$

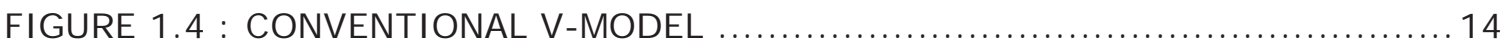

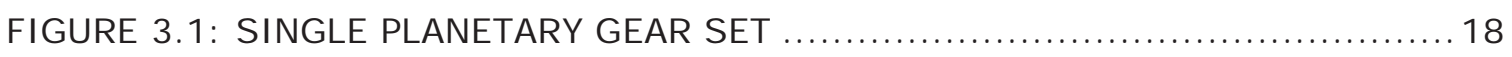

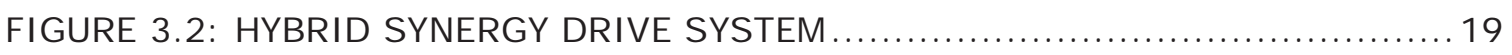

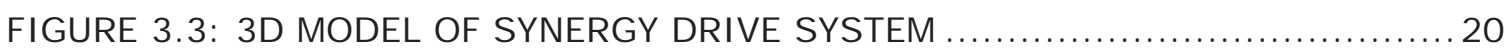

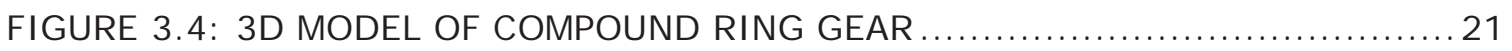

FIGURE 3.5: 3D MODEL OF THS III PLANETARY GEAR SET $\ldots \ldots \ldots \ldots \ldots \ldots \ldots \ldots \ldots \ldots \ldots \ldots \ldots \ldots \ldots \ldots$

FIGURE 3.6: FREE BODY DIAGRAM OF SUN GEAR 1 (S1) AND SUN GEAR 2 (S2) ... 23

FIGURE 3.7: FREE BODY DIAGRAM OF COMPOUND RING GEAR $\ldots \ldots \ldots \ldots \ldots \ldots \ldots \ldots . \ldots \ldots$

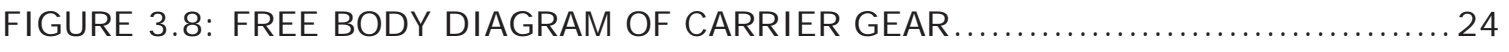

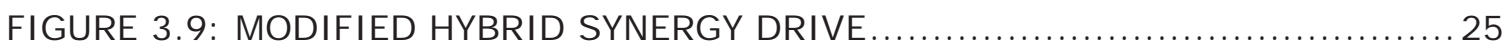

FIGURE 3.10: POWER-SPLIT POWERTRAIN IN ELECTRIC ONLY MODE $\ldots \ldots \ldots \ldots \ldots . . \ldots 27$

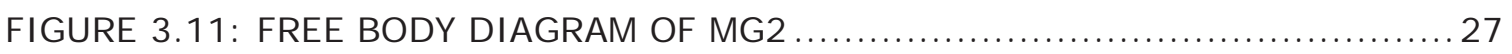

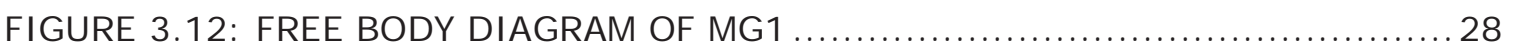

FIGURE 3.13: POWER-SPLIT POWERTRAIN IN HYBRID MODE $\ldots \ldots \ldots \ldots \ldots \ldots \ldots \ldots \ldots \ldots \ldots \ldots \ldots \ldots \ldots$

FIGURE 3.14: FREE BODY DIAGRAM OF ENGINE CONNECTED TO CARRIER $\ldots \ldots \ldots . . .30$

FIGURE 3.15: FREE BODY DIAGRAM OF MGI IN HYBRID MODE $\ldots \ldots \ldots \ldots \ldots \ldots \ldots \ldots \ldots \ldots \ldots \ldots \ldots$

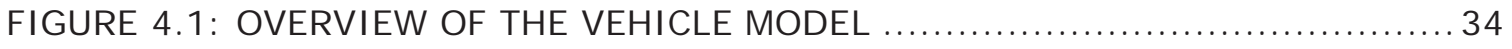

FIGURE 4.2: CONTROL STRATEGY TO SELECT VEHICLE MODE $\ldots \ldots \ldots \ldots \ldots \ldots \ldots \ldots \ldots \ldots$

FIGURE 4.3: VEHICLE ARCHITECTURE ..................................... 39

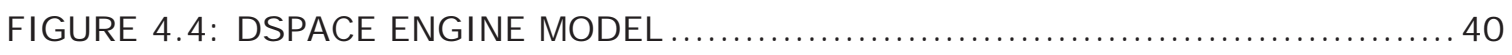

FIGURE 4.5: MG2 AND MG1 MOTOR EFFICIENCY MAP $\ldots \ldots \ldots \ldots \ldots \ldots \ldots \ldots \ldots \ldots . \ldots 1$ 
FIGURE 4.6: DSPACE ELECTRIC COMPONENTS MODEL $\ldots \ldots \ldots \ldots \ldots \ldots \ldots \ldots \ldots \ldots . \ldots 2$

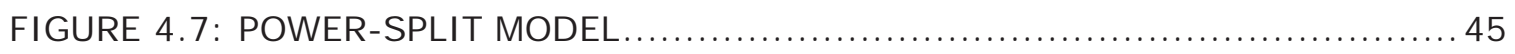

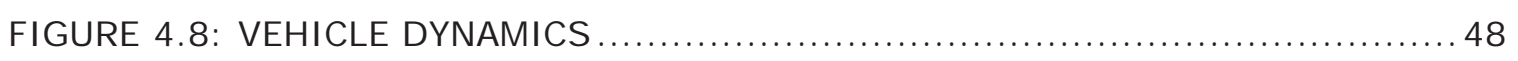

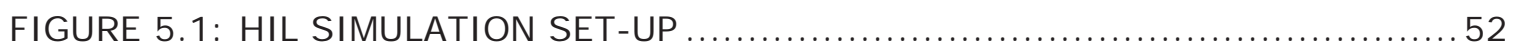

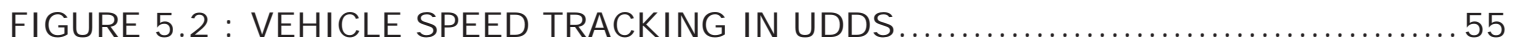

FIGURE 5.3: COMPARISON OF REQUESTED ICE TORQUE AND GENERATED ICE

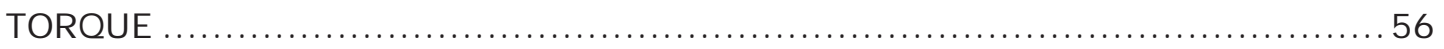

FIGURE 5.4: COMPARISON OF BATTERY SOC WITH SOC UPPER LIMIT ..............57

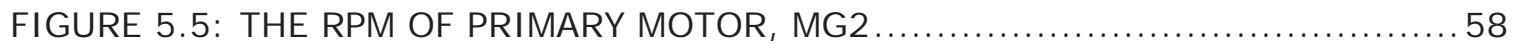

FIGURE 5.6: THE RPM OF SECONDARY MOTOR MG1 .......................... 59

FIGURE 5.7: COMPARISON OF ICE MODE CHANGE WITH VEHICLE VELOCITY .......60

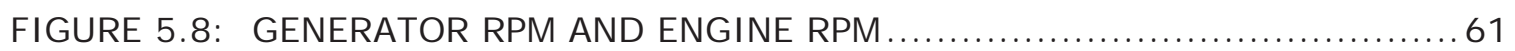

FIGURE 5.9: VEHICLE AND ICE MODE COMPARISON WITH POWERTRAIN

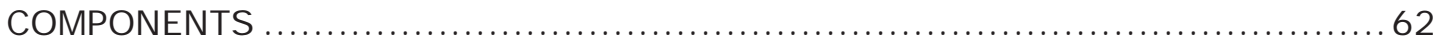

FIGURE 5.10: ENGINE OPERATING POINTS IN BSFC MAP OF 2.9 LITER ENGINE ....63 FIGURE 5.11: MG2 MOTOR OPERATING POINTS ON MOTOR EFFICIENCY MAP ....... 64 


\section{ST OF TABLES}

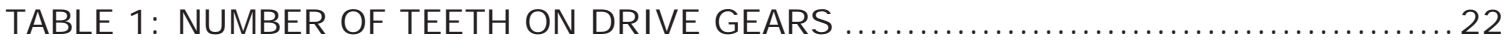

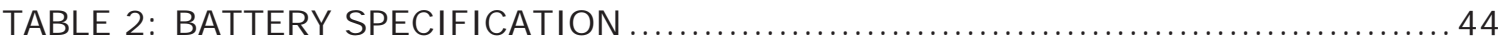

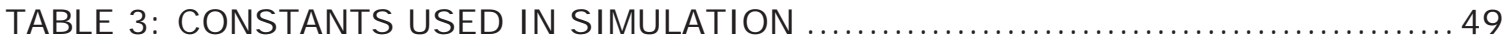

TABLE 4 : THE CONNECTIONS BETWEEN HIL SIMULATOR AND MICROAUTOBOX....53 


\section{ACKNOWLEDGEMENTS}

I thank my advisor Dr. Bo Chen, for support in this research work and guiding me for my Masters education. I would like to thank committee member Dr. John Beard and Dr. Zhuo Feng for being in the committee and all their suggestions.

I am grateful to all my Intelligent Mechatronics and Embedded Systems Lab colleagues at Michigan Technological University special thanks to Yang Li and Ming Cheng for their help and support in my research.

I would like to thank all my friends I made at Michigan Tech. I admire your help and support through all good and bad times.

Finally, आई, बाबा आणि दादाला कोटी कोटी प्रणाम... 


\section{ABSTRACT}

Conventional vehicles are creating pollution problems, global warming and the extinction of high density fuels. To address these problems, automotive companies and universities are researching on hybrid electric vehicles where two different power devices are used to propel a vehicle. This research studies the development and testing of a dynamic model for Prius 2010 Hybrid Synergy Drive (HSD), a power-split device. The device was modeled and integrated with a hybrid vehicle model. To add an electric only mode for vehicle propulsion, the hybrid synergy drive was modified by adding a clutch to carrier 1 . The performance of the integrated vehicle model was tested with UDDS drive cycle using rule-based control strategy. The dSPACE Hardware-In-the-Loop (HIL) simulator was used for HIL simulation test. The HIL simulation result shows that the integration of developed HSD dynamic model with a hybrid vehicle model was successful. The HSD model was able to split power and isolate engine speed from vehicle speed in hybrid mode. 


\section{I NTRODUCTI ON}

The fossil fuels are being utilized as main sources of energy for most of the power producing applications. Due to the fast depletion of oil resources, the remaining reserves are expected to approach to zero around 2040 as shown in Figure 1.1. The limited resources of oil also cause the raising of oil prices every year. In addition to the loss of crucial energy resources of very high energy density, the global warming is also a severe issue. One of the major contributors to global warming is the $\mathrm{CO}_{2}$ emissions of conventional vehicles. Figure 1.2 shows that the $\mathrm{CO}_{2}$ emission from transportation is very close to the amount generated by industry.

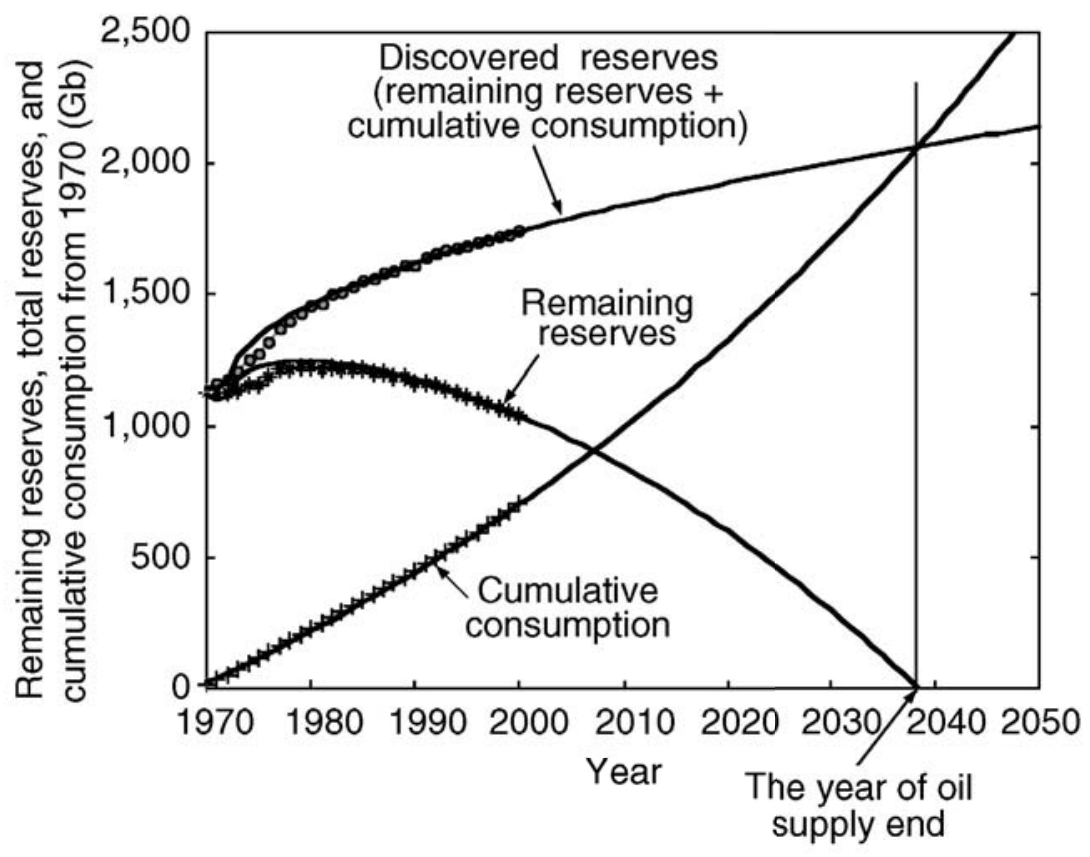

Figure 1.1: Projected demand and supply of oil reserves [1]. 


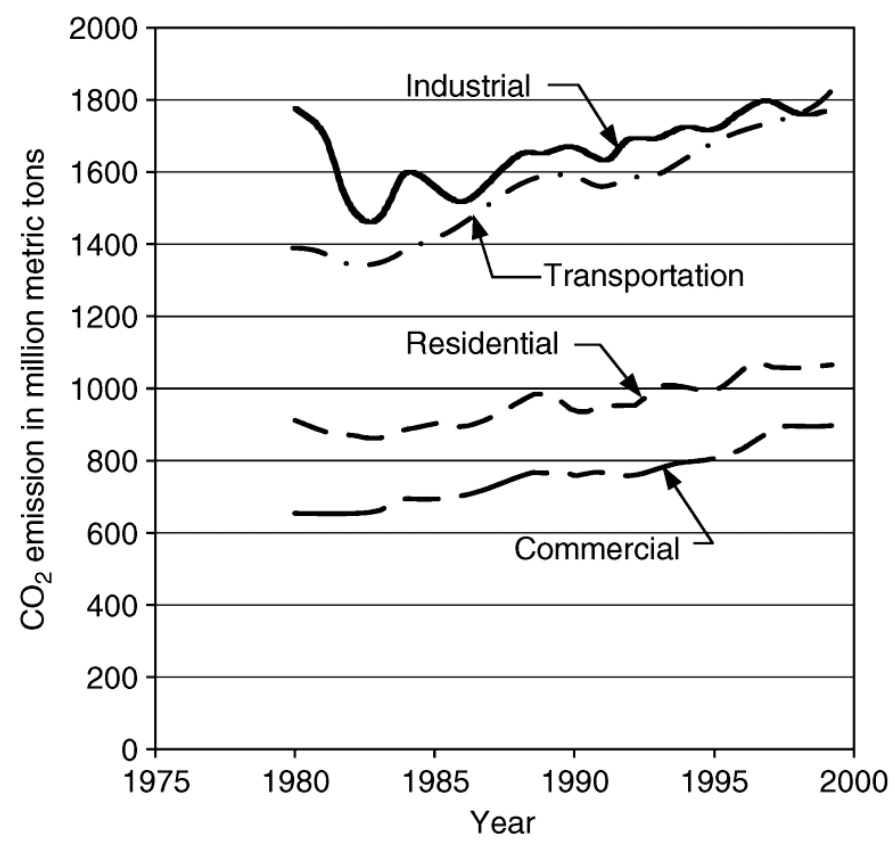

Figure 1.2: $\mathrm{CO}_{2}$ emissions from various sources [2].

The rise of $\mathrm{CO}_{2}$ emission causes the increase of global temperature. Figure 1.3 shows temperature being steady till almost 1900. Since the inception of Internal Combustion Engine (ICE) into vehicles and transportation, temperature is rising steadily. With growing economy, the number of conventional automobiles sold will be increasing. As ICE efficiency is limited to the Carnot cycle efficiency, a technological advantage has to be gained so that the extinction of fossil reserves doesn't hamper the growth of humanity. To limit $\mathrm{CO}_{2}$ emissions and increase the efficiency of vehicles, government is implementing higher CAFÉ standards which all the automobile manufactures need to follow. 


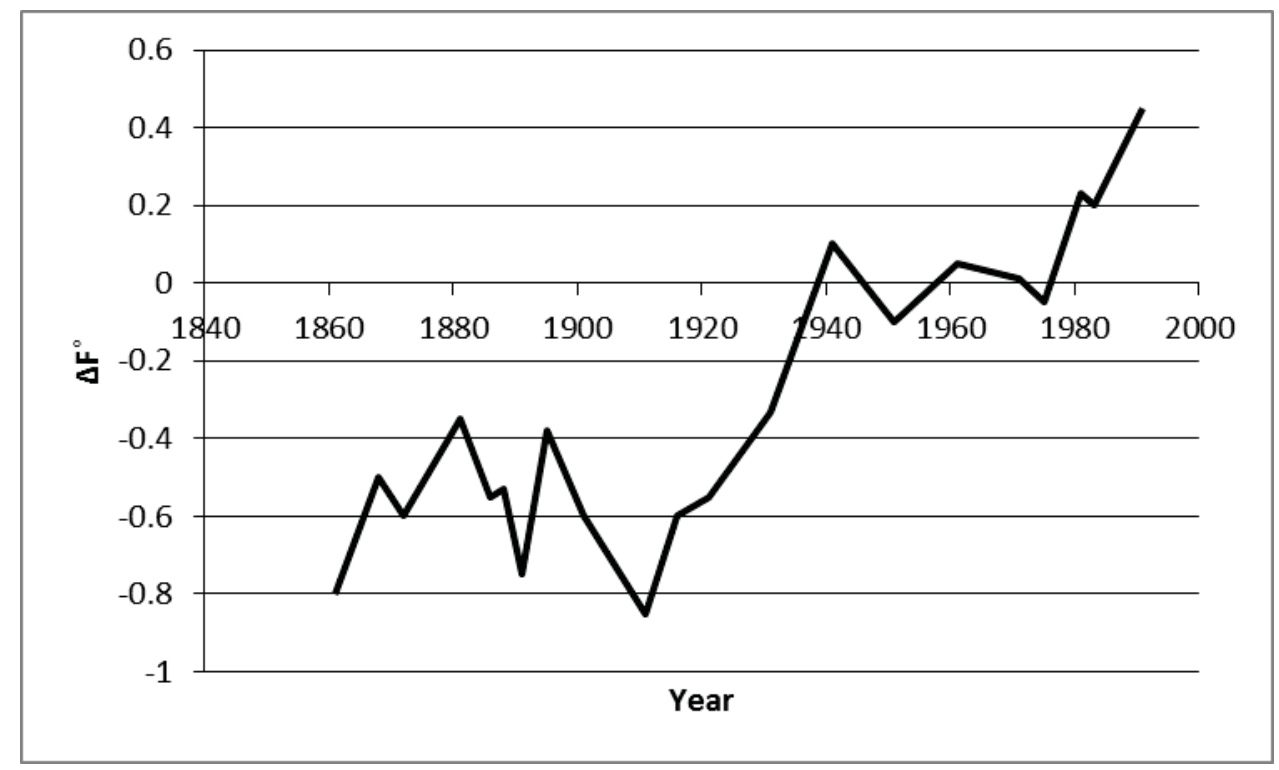

Figure 1.3: Change in temperature since introduction of ICE [1].

The efficiency of conventional vehicles can only been improved to a certain extent due to the limitation of energy conversion and heat losses. To overcome this limitation, hybridization of the powertrain is one of the solutions. Hybrid vehicles are powered by ICE and electric motors. There are two significant advantages of this powertrain combination. One is the high efficiency of motor at higher torque and the other is regenerative braking, which allows putting the mechanical energy back into power source (battery).

Till date, research on Hybrid Electric Vehicle (HEV) is of three basic types. The first type is series hybrid. For a series hybrid vehicle, ICE charges battery while e-motor drives car throughout drive cycle. The second type is parallel hybrid, where either emotor or the ICE or both are driving the vehicle at same time. The third type is power-split, where either e-motor/ICE can drive at once or both can work simultaneously while charging the battery. The engine Rotation Per Minute (RPM) in power-split vehicles is isolated from vehicle speed to achieve maximum miles/\$. The power-split allows a vehicle to act as parallel or series when needed. This comes at a cost of added complexity to the overall system but proves to be beneficial in engine optimization. 
Currently, the vehicle electrification is bound by limited storage capacity of batteries and long charging hours. Though there are some commercial manufacturing industries like Tesla Motors Inc. which are involved in selling of complete electric vehicle, long charging time and vehicle range anxiety scares customers away from buying a pure electric vehicle. The power-split and plug-in hybrid electric vehicles are best available compromise which can be implemented to lay foundation for the full electrification plan. The plug-in hybrid electric vehicles allow charging of batteries from the home power supply. The Volt introduced by General Motors is the prime example of plug-in hybrid electric vehicles.

Any new powertrain design needs to be tested. The conceptual idea of hybrid vehicle and its testing for commercial implementation could cost a lot of money to a company. In basic vehicle designing process, firstly, the size and type of powertrain is decided. Once the size of powertrain is decided, economy of a vehicle can be greatly improved by implementing right control strategy. To validate whether the implemented control strategy is optimum, a good mathematical model of all working systems is necessary. The software-in-loop (SIL) and hardware-in-loop (HIL) testing methods are used in testing and modification of hybrid vehicles.

The control strategy development can be implemented in two ways, with conventional V-model as shown in Figure 1.4 [3] and model-based design. In conventional V-model algorithm, the control specification is firstly designed. Then, the system level and subsystem level control are designed and implemented. The test of the control objectives are started from subsystems, system level, and then finally integrated with vehicles. With a number of iterations, the $\mathrm{V}$-model design and test process becomes inefficient. Model-based design allows the designer and his team to switch within any level of vehicle development avoiding time losses due to testing and engineering hours. In model-based design, mathematical models are implemented in graphical format which also makes debugging of algorithms very easy. 


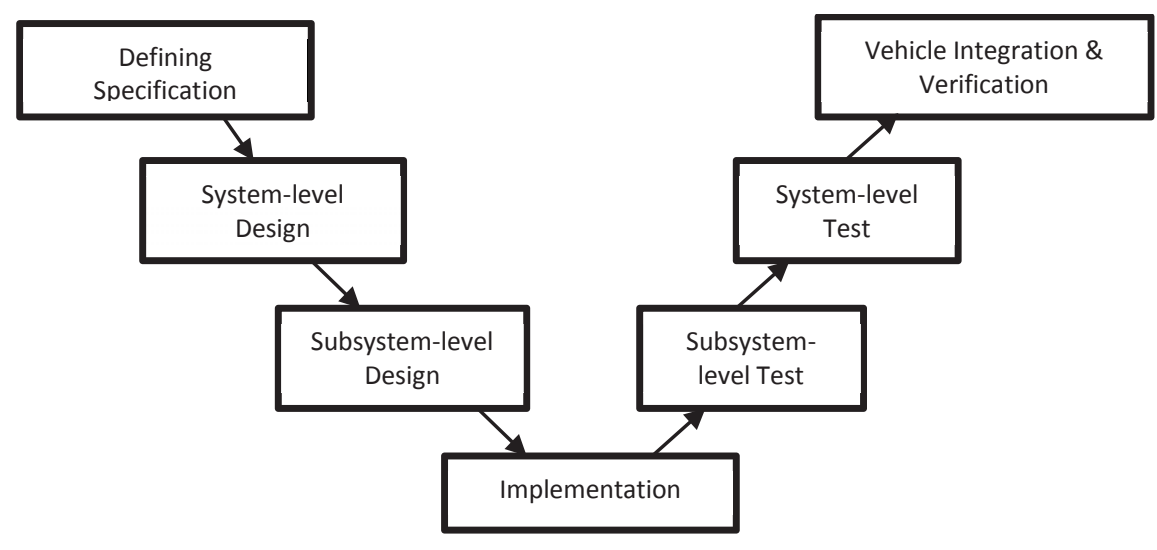

Figure 1.4 : Conventional V-model

The mathematical models are created in coding platform of computer. The coded system can first be validated in software platform using software-in-the-loop test. If the performance is appropriate, the machine code of the developed models will be generated and downloaded to Electronic Control Unit (ECU) or the HIL processor board for HIL testing of the system. HIL test of mathematical models are in real-time on a simulator. In this report, an ECOLine HIL simulator developed by dSPACE Inc. is used to run simulation. The dSPACE simulator is equipped with a RTI 1006 processor board for real-time simulation. An ECU can be a hardware ECU or a softECU. One motor ECU uses dSPACE MicroAutobox II. The other ECUs are softECUs. The simulator is calibrated using a licensed copy of ControlDesk 7.2 software. The ControlDesk has a user friendly Graphics User Interface (GUI). ControlDesk GUI allows us to build different layouts and measuring panels to run and calibrate experiments in real-time. The dSPACE package comes with two completed models of a conventional ICE vehicle and a parallel hybrid electric vehicle. The models can be edited in Simulink platform. Auto-code generation software converts the Simulink models into $\mathrm{C}$ language code. This code can be easily compiled into machine code for microprocessors. For this project, HIL simulator along with MicroAutobox is being used to simulate a complete power-split hybrid vehicle in ControlDesk environment.

The report has been organized in following chapters.

Chapter 1: discusses the motivation and need for this research work.

Chapter 2: literature review of various power-split configurations and control strategies. 
Chapter 3: dynamic model of power-split HEV, including all the mathematical equations needed for the development of power-split model.

Chapter 4: HIL simulation model, including the overview of vehicle model, vehicle ECU network, vehicle plant model, sensors and actuators.

Chapter 5: HIL simulation results and discussions.

Chapter 6: conclusions and future work. 


\section{LITERATURE REVIEW}

Type of powertrain architecture plays significant role in improving economy of a HEV. Series architecture helps in city driving conditions or a drive cycle with a lot of starts and stops. A parallel vehicle helps in highway drive cycle to improve fuel economy. A power-split architecture is a combination of parallel and series vehicles but adds the complexity to vehicle in design and assembly. The power-split architecture also allows more freedom in control strategy development.

\subsection{Power-split Hybrid Electric Vehicle Configurations}

A Power-split HEV can have various configurations of itself. A basic power-split is with one planetary gear set, which is most commonly used and has being implemented in Toyota Prius and its various generations [4]. A comparison between two-mode hybrid transmission and II $^{\text {nd }}$ generation of Toyota Hybrid System (THS) was done by Aimin and Hongwei [5]. The two mode transmission has three planetary gear sets along with two electric motors and an engine. It was awarded technology of the year of 2007. The system is complex masterpiece of engineering with four clutches and four fixed gear modes. It allows good speed range with higher transmission efficiencies and also gives a choice to reduce the electric motor power rating at design stage compared to a rigid THS single mode system [5]. Chevrolet Volt is another commercially available single planetary power-split vehicle. It has three clutches incorporated as output split to get higher efficiencies compared to Toyota hybrid system with no clutches. These three clutches allow the vehicle to run in four different modes. The comparison study of THS single mode and Chevrolet Volt powertrain was done by graduate students at University of Michigan. The study found that adding one clutch to Toyota hybrid system improves efficiency of the vehicle by $16.13 \%$ while reducing two clutches from the Volt decreases efficiency by $0.8 \%$ [6]. A single planetary gear set can have numerous configurations of powersplit. With addition of each planetary gear set, the degree of freedom increases and the number of combinations to get desired vehicle velocity and torque also increase. Dr. Jinming Liu worked on the algorithm to design and identify various configurations of planetary gear set models and their dynamic equations [7]. 


\subsection{HEV Control Strategies}

The work on the various control algorithms is one of the most influencing parts of the HEV's. The control algorithm affects the power plants performance and eventually vehicle performance. There is significant amount of research being conducted and a number of control strategies are developed. Poowanart Poramapojana, a graduate student from Michigan Tech, has conducted a literature review of control strategies in his thesis research [8]. A lot of work by various researchers is on stochastic control and dynamic programming. Dr. Jinming Liu worked on Stochastic Dynamic Programming (SDP) and Equivalent Consumption Minimization Strategy (ECMS) [9] and found that these control strategies can improve the fuel economy of a powersplit hybrid vehicle. The limitation of the SDP approach is its amount of computation required. Though a dynamic programming algorithm is faster compared to standard stochastic control, long computing time and heavy computational need make them not suitable for the real-time and real world applications with current generation of embedded systems. ECMS is more suitable for real world application but it is not robust enough to apply to a vehicle with no predetermined drive cycle. The AdaptiveECMS (A-ECMS) control strategy [10] is very similar to ECMS implemented by Musardo. He tried to eradicate the problem of less robustness by implementing an adaptive algorithm. This algorithm collects and calculates the data using GPS before driving condition is reached. This allows a vehicle to decide control parameters beforehand. But not all of vehicles are equipped with GPS and the signal distortion in remote areas can hamper a vehicle's performance in reducing its fuel economy rapidly. The A-ECMS algorithm is designed and implemented for a parallel vehicle. This algorithm gives fuel economy values very close to dynamic programming with very less computational load. Pontryagin's Minimum Principle (PMP) is another control strategy which can be implemented for real-time applications [11]. The PMP algorithm, when implemented on a power-split vehicle, gives results very close to the dynamic programming. 


\section{DYNAMI C MODEL OF POWER-SPLIT HEV POWERTRAI N}

The power-split HEV powertrain architecture has been studied extensively in literature. There are several variants of power-split powertrain in market. A single mode in THS I and II is the simplest system with one planetary gear set [4]. THS III, also called as Hybrid Synergy Drive, uses 2 planetary gear sets. THS III has a second carrier gear which is fixed to transmission cover and a compound ring gear [12]. All the THS systems have a motor (MG2), an engine and a generator (MG1).

\subsection{SI NGLE PLANETARY GEAR SET}

Figure 3.1 shows a single planetary gear set.

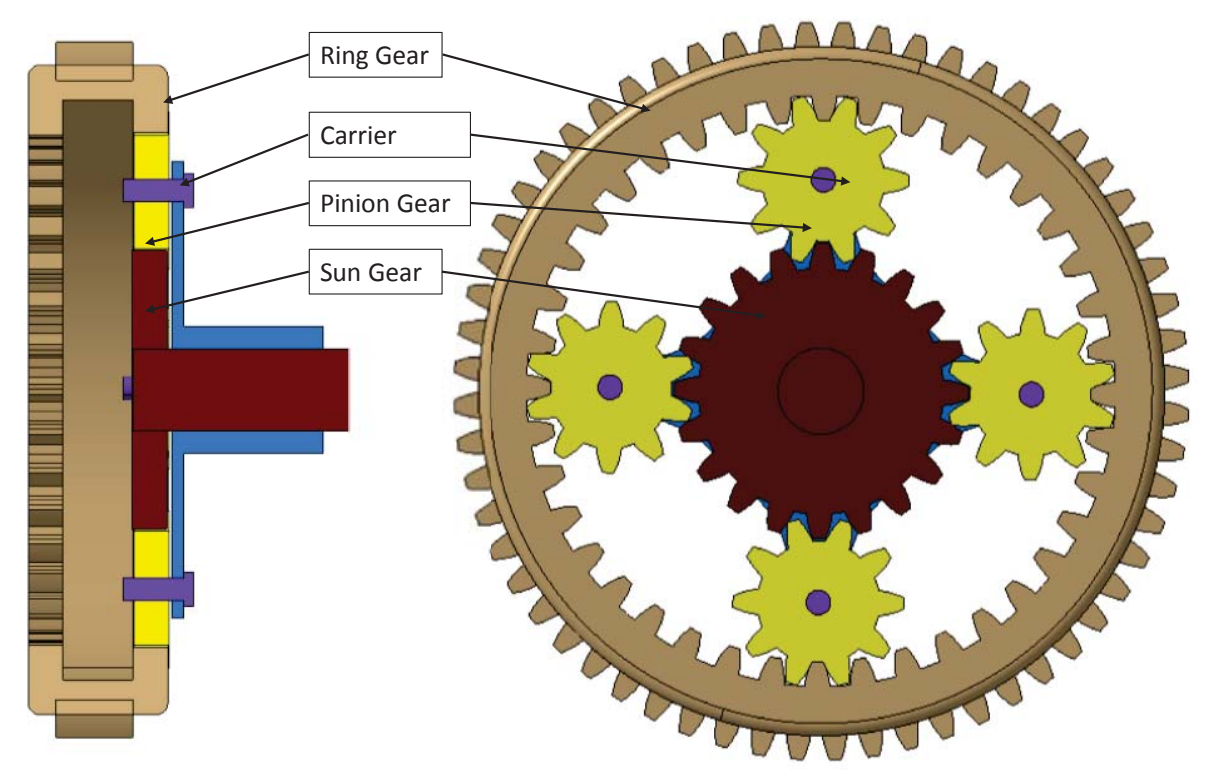

Figure 3.1: Single planetary gear set

The Planetary Gear (PG) set was modeled with basic equation of kinematic constraints given by Willis [13] as shown in Eq. 1 .

$$
\omega_{r} \cdot R_{r}+\omega_{s} \cdot R_{s}=\left(R_{r}+R_{s}\right) \cdot \omega_{c}
$$

Eq. 1

where $\omega_{r}, \omega_{s}$ and $\omega_{c}$ is angular velocity of ring, sun and carrier, respectively, and $R_{r}$ and $R_{s}$ are radius of ring and sun gears. This equation defines the overall kinematic 
behavior of the planetary gear set. The equation allows only 2 speed inputs while the third one has to follow as per the equation.

The simple planetary gear set, used in THS 2004 system, has been studied by Liu J. [7] and Poramapojana, P. [8] in their dissertation and thesis, respectively. In this report the $3^{\text {rd }}$ generation of THS system (THS III), Hybrid Synergy Drive, has been studied.

\subsection{HYBRI D SYNERGY DRI VE}

Figure 3.2 shows the 2 dimensional diagram of the Hybrid Synergy Drive.

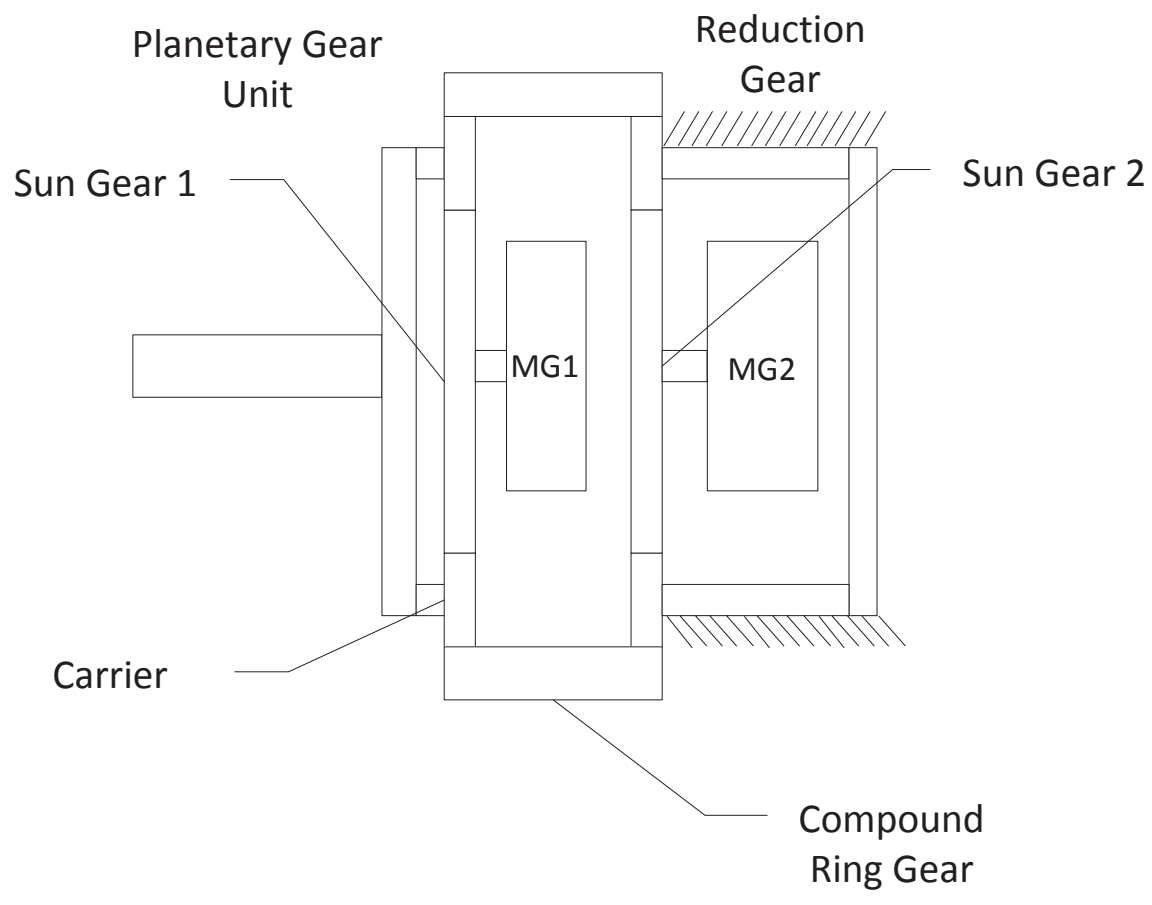

Figure 3.2: Hybrid synergy drive system

Figure 3.3 shows the THS III system, it has a compound ring gear with 3 sets of teeth as shown in Figure 3.4. The external gear teeth are used to drive the wheels using a differential gear set. Figures 3.1, 3.3-3.5 were generated from the CAD software CATIA V5 to help understanding the complexity of hybrid synergy drive system. The set on the side of orange planetary gears is that of MG2 and is a reduction gear unit. The other side is for MG1 having planetary gear unit. One 
planetary gear set, shown in Figure 3.5 is used as power-split device. The powersplit device has engine connected to carrier, the MG1 is connected to sun gear 1, as shown in Figure 3.2. This power-split device splits the power provided by the engine towards the sun gear that has MGl attached to it and the other side of the compound ring gear connects to a MG2. The ring gear structure allows $20 \%$ size reduction of power-split device from earlier generation of gear drive [12]. The compact ring gear removes the chain drive presented in the 2 nd generation of THS system. The other planetary gear set is a MG2 speed reduction device. The carrier of the planetary gear contains spline which is fixed to the transmission casing.

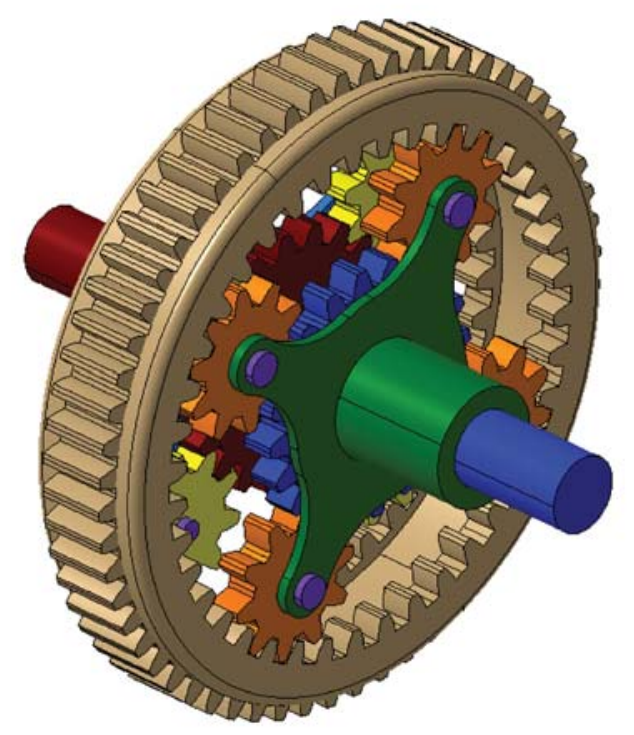

Figure 3.3: 3D model of synergy drive system 


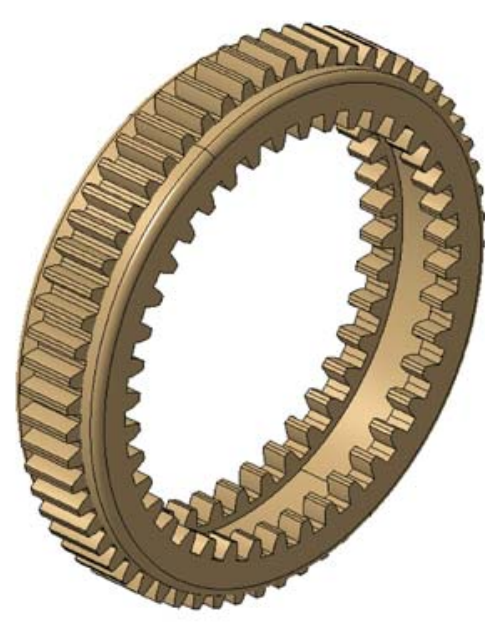

Figure 3.4: 3D model of compound ring gear

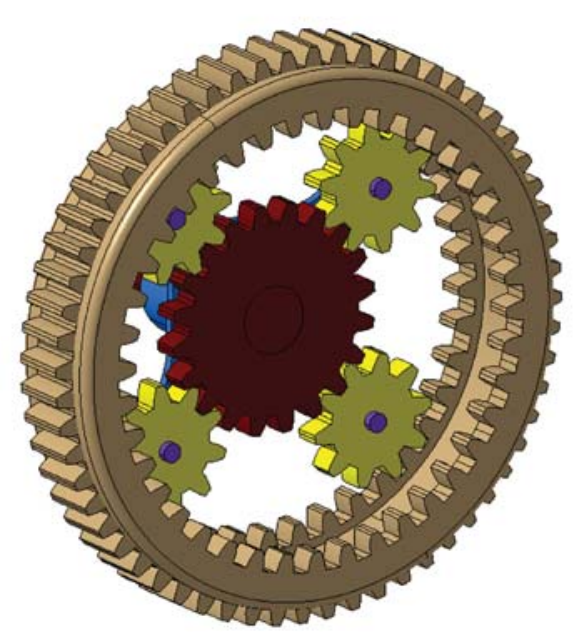

Figure 3.5: 3D model of THS III planetary gear set

Table 1 shows that all the gear teeth of the synergy drive system used in Toyota Prius 2010. The fixed reduction gear allows ring and MG2 to rotate in different direction with respect to each other. This also reduces number of axis required as the MG2 will have the same axis as MG1 and the engine [12]. The THS II power-split drive study done by Jerome Meisel [4] explains that the maximum speed of MG1 in both direction of rotation is the key factor in deciding the engine start and its maximum speed. As THS II does not have any speed reduction for MG2, it was directly connected to ring gear. Hence, the RPM of MG1 would reach the speed limit faster than needed, as the MG1 experiences higher speeds. Gear reduction of second planetary gear in hybrid synergy drive system allows ring rotations to be lower and MG2 rotations to be close to MG1 rotations. The reduction device has gear ratio 2.6 $\left(\frac{\text { No. of ring gear } 2 \text { teeth }}{\text { No. of sun gear } 2 \text { teeth }}=\frac{78}{30}=2.6\right)$ as per the number of gear teeth/radius of each gear. The reduced ring RPM removes the kinematic constrain of MG1 and allows the vehicle to be propelled in only EV mode at higher speeds. The final gear ratio of THS III has been reduced compared to THS II from 4.113 to 3.2 $\left(\frac{\text { No. of final drive gear teeth }}{\text { No. of driven gear teeth }}=\frac{77}{24}=3.2\right)$ [14]. This reduced final gear ratio allows lesser power loss occurring due to power conversion from MG1 speed reversing on highway drive cycles compared to THS II [15]. 
Table 1: Number of teeth on drive gears

\begin{tabular}{|c|l|l|}
\hline $\begin{array}{c}\text { Section of Power- } \\
\text { split }\end{array}$ & \multicolumn{1}{|c|}{ Gear } & \multicolumn{1}{|c|}{$\begin{array}{c}\text { No. of gear } \\
\text { teeth }\end{array}$} \\
\hline \multirow{4}{*}{ Power-split side } & Ring 1 & 58 \\
\cline { 2 - 3 } & Pinion 1 & 23 \\
\cline { 2 - 3 } & Sun 1 & 22 \\
\hline \multirow{3}{*}{ Reduction side } & Ring 2 & 78 \\
\cline { 2 - 3 } & Pinion 2 & 18 \\
\cline { 2 - 3 } & Sun 2 & 30 \\
\hline \multirow{2}{*}{ Other gears } & Counter Drive and Driven gear & $54-55$ \\
\cline { 2 - 3 } & Final Drive and Driven Gear & $24-77$ \\
\hline
\end{tabular}




\subsection{Dynamics of THS III Gear Train (Hybrid Synergy Drive)}

The assumptions for mathematical modeling of compound planetary gear set are as follows. The clock-wise rotation of ring, carrier and sun gear is considered as positive while the counter clockwise is considered as negative. The inertia of ring, sun and carrier arm is considered while pinion inertia has been neglected as it is a very small value. The pinion experiences force which is transmits towards ring/sun depending upon the direction of energy flow. The THS III has 2 sections, one is generator side which is a complete single planetary gear set with all subscript 1 and another is reduction gear set with subscript 2. The equations for Free Body Diagram (FBD) shown in Figure 3.6, Figure 3.7 and Figure 3.8 are given in Eq. 2-Eq. 5

$$
\begin{array}{lr}
I_{s 2} \dot{\omega}_{s 2}=F_{2} \cdot R_{s 2}-T_{s 2} & \text { Eq. } 2 \\
I_{r} \dot{\omega}_{r}=F_{1} \cdot R_{r 1}+F_{2} \cdot R_{r 2}-T_{r} & \text { Eq. } 3 \\
I_{c 1} \dot{\omega}_{c 1}=T_{c 1}-F_{1} \cdot R_{r 1}-F_{1} \cdot R_{s 1} & \text { Eq. } 4 \\
I_{s 1} \dot{\omega}_{s 1}=F_{1} \cdot R_{s 1}-T_{s 1} & \text { Eq. } 5
\end{array}
$$

The $I_{r}, I_{c 1}, I_{s 1}$ and $I_{s 2}$ are mass moment of inertia of ring, carrier 1 , sun gear 1 and sun gear 2 with units of $\mathrm{kg} \cdot \mathrm{m}^{2} . \dot{\omega}_{\mathrm{r}}, \dot{\omega}_{\mathrm{c} 1}, \dot{\omega}_{\mathrm{s} 1}$ and $\dot{\omega}_{\mathrm{s} 2}$ are the angular acceleration of ring, carrier 1 , sun gear 1 and sun gear 2 with units of $\mathrm{rad} / \mathrm{s}^{2} . \mathrm{T}_{\mathrm{r}}, \mathrm{T}_{\mathrm{c} 1}, \mathrm{~T}_{\mathrm{s} 1}$ and $\mathrm{T}_{\mathrm{s} 2}$ are torque of ring, carrier 1 , sun gear 1 and sun gear 2 with units of $\mathrm{Nm} . \mathrm{F}_{1}$ is the internal force acting on ring and sun gear 1 via pinion gear on generator side and $\mathrm{F}_{2}$ is internal force acting on ring and sun gear 2 due to pinion gear on motors side of the compound gear set. There is no equation for the carrier 2 as it is fixed to ground.
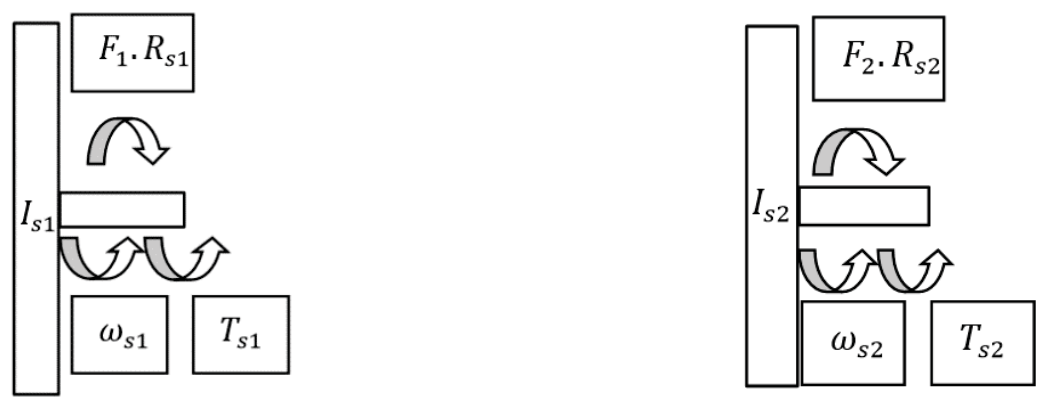

Figure 3.6: Free body diagram of sun gear 1 (S1) and sun gear 2 (S2) 


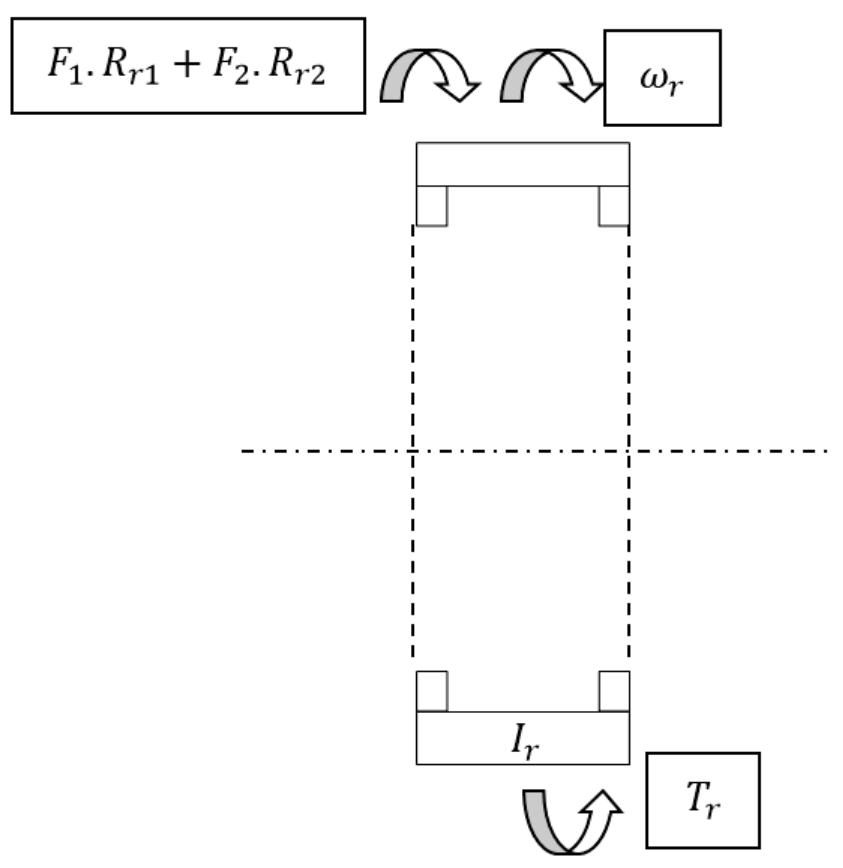

Figure 3.7: Free body diagram of compound ring gear

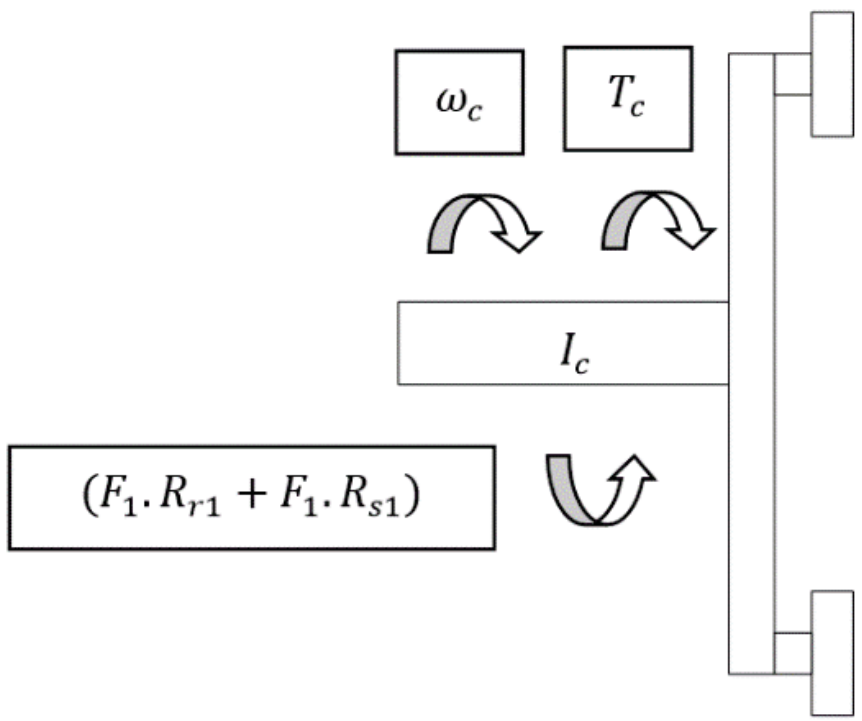

Figure 3.8: Free body diagram of carrier gear 


\subsection{Modified Hybrid Synergy Drive}

Figure 3.9 shows the modified hybrid synergy drive system. A simple clutch has been added to carrier 1 . This allows the carrier on planetary gear side to be grounded at will and adds an extra dimension in control functionality of the vehicle as MG1 and MG2 both act as motors.

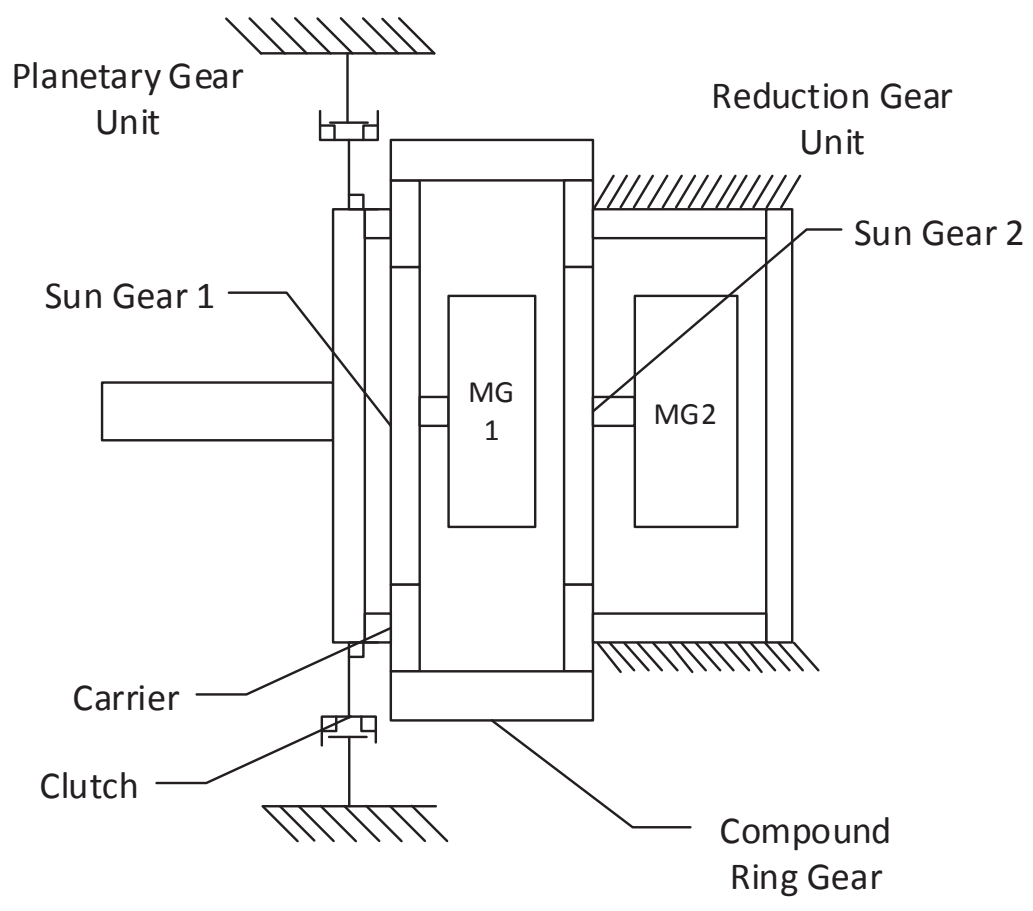

Figure 3.9: Modified hybrid synergy drive

The study done by Xiaowu and his colleagues [6] showed that an added clutch to the THS 2004 system helps in improving the economy by $16.132 \%$ compared to simple planetary gear train. Figure 3.9 has added a clutch which allows the vehicle to operate in 2 modes, Electric Only (EV) mode and Hybrid mode. As the carrier gear 1 gets fixed, it provides the reaction torque necessary so that power-split doesn't occur and planetary gear acts as reduction device. Hence, the route of the MG1 power flow is restricted to flow towards ring and then towards the wheels. The EV only mode would allow vehicle to be moved without any engine operation. The reduction gear set removes kinematic constrain (Eq.1) imposed by the MG1 speed as long as the 
clutch is engaged. The gear ratios show that the gear reduction unit has a gear ratio of $2.6\left(\frac{N_{r 2}}{N_{s 2}}=\frac{78}{30}\right)$ almost equaling to planetary gear ratio of $2.6363\left(\frac{N_{r 1}}{N_{s 1}}=\frac{58}{22}\right)$.

\subsection{Dynamic Model of Hybrid Synergy Drive with Clutch}

Two planetary gear sets can be reduced to 1 planetary gear set as carrier 2 is grounded. Now if carrier 1 is grounded as well, the $\omega_{c 1}=0$ and the sun gear 1 can be related to the ring gear by Eq. 6

$$
\omega_{r}=-\omega_{s 1} \cdot \frac{R_{s 1}}{R_{r 1}}=-\omega_{s 1} \cdot \frac{N_{s 1}}{N_{r 1}}=-\omega_{s 1} \cdot \rho_{1} \quad \text { Eq. } 6
$$

where, $N_{s 1}$ and $R_{s 1}$ is the number of teeth and radius of sun gear $1 . N_{r 1}$ and $R_{r 1}$ are the number of teeth and radius of compound ring gear on MGI side. As sun gear is related via pinion and internal gear of ring, the direction of rotation of both the sun gears and compound ring gear are opposite. For all dynamics, $\omega_{s 1}=\omega_{g}$ where $\omega_{g}$ is the angular velocity of the generator and $\omega_{s 2}=\omega_{m}$ is the angular velocity of the motor. No elastic losses between motor/generator shafts and gears are considered.

\subsubsection{Electric Only mode (EV)}

In EV mode, the clutch of carrier gear 1 is fixed to the ground creating the reaction torque when MG1 acts as a motor. The planetary gear turns to 2 sets of reduction gears as shown in Figure 3.10. 


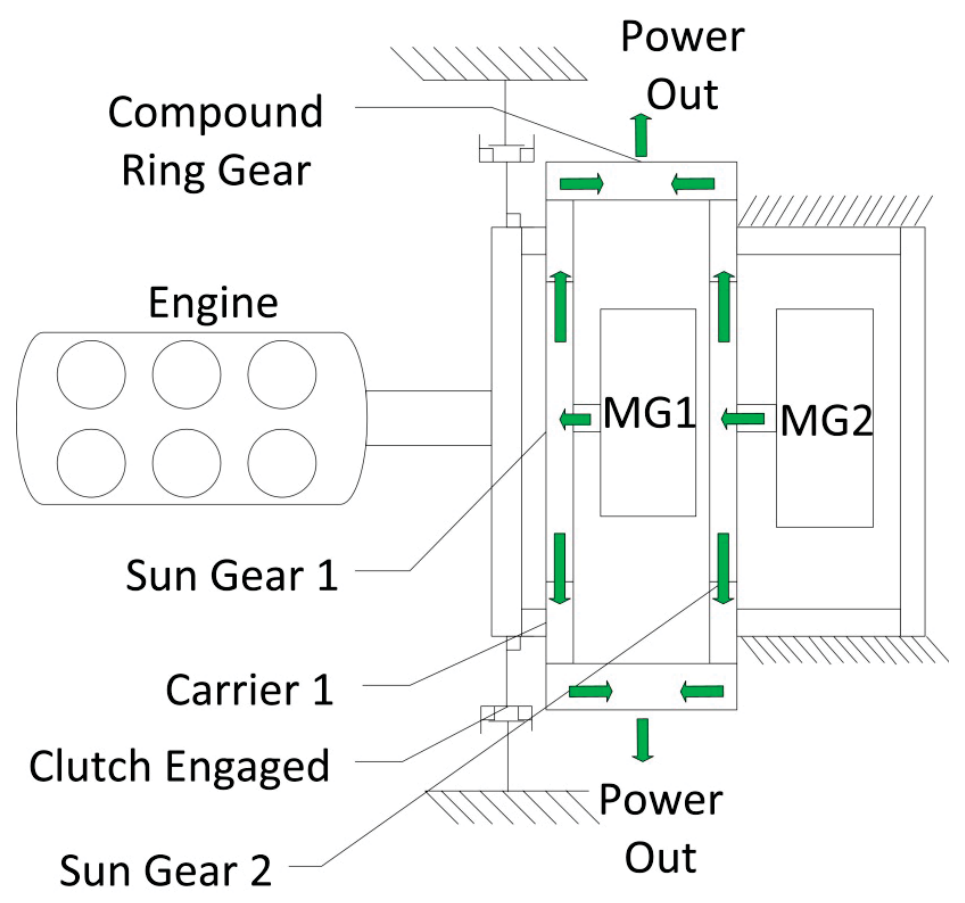

Figure 3.10: Power-split powertrain in electric only mode

\subsubsection{MG2 Dynamics in EV mode}

The free body diagram of MG2 is shown in Figure 3.11.

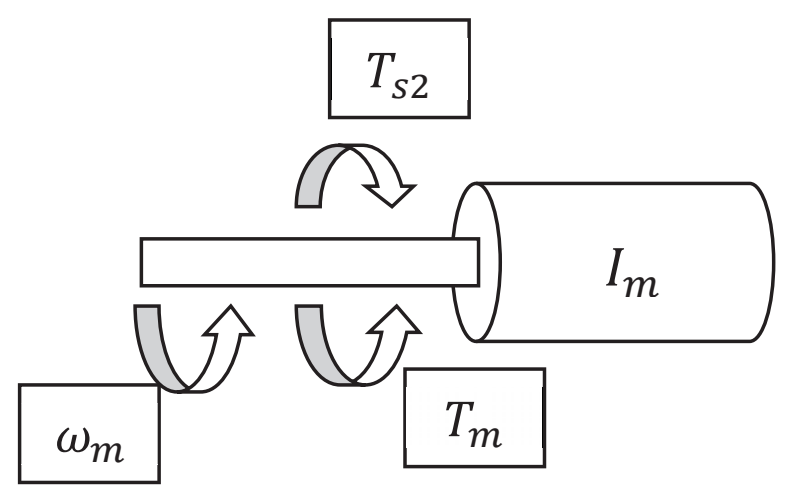

Figure 3.11: Free body diagram of MG2

$$
I_{m} \dot{\omega}_{m}+T_{m}=T_{s 2}
$$

Eq. 7

Substituting $T_{s 2}$ in Eq. 2 to get the value of internal pinion force $F_{2}$ 


$$
F_{2}=\frac{\left(I_{s 2}+I_{m}\right) \dot{\omega}_{s 2}+T_{m}}{R_{s 2}}
$$

\subsubsection{MG1 Dynamics in EV mode}

The free body diagram of MG1 is shown in Figure 3.12.

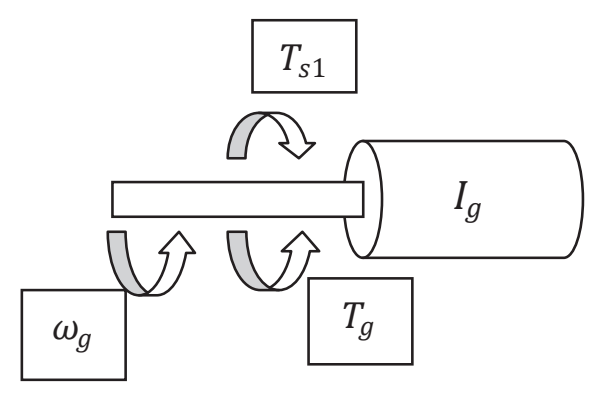

Figure 3.12: Free body diagram of MG1

$$
I_{g} \dot{\omega}_{g}+T_{g}=T_{s 1}
$$

Eq. 9

Substituting $T_{s 1}$ in eq. 5 to get the value of internal pinion force

$$
F_{1}=\frac{\left(I_{s 1}+I_{g}\right) \dot{\omega}_{s 1}+T_{g}}{R_{S 1}}
$$

Substituting values $F_{1}$ and $F_{2}$ into eq. 3, where $\dot{\omega}_{s 1}=\dot{\omega}_{g}$ considering no elastic losses in carrier gear. The ratio of sun and ring gear at MG1 and MG2 is given by $\frac{R_{S 1}}{R_{r 1}}=\rho_{1}$, $\frac{R_{s 2}}{R_{r 2}}=\rho_{2}$. As both are reduction gear sets, ring gear is related to motor and generator angular velocities by $\dot{\omega}_{r}=-\dot{\omega}_{m} \rho_{2}=-\dot{\omega}_{g} \rho_{1}$. The torque acting on ring gear due to torque at wheels is given by $T_{r}=\frac{T_{w}}{G_{d}}$. This is the reaction torque due to the resistance offered by vehicle dynamics at ring gear. The EV mode is given by Eq.11,

$$
\left\{\frac{m r^{2}}{G_{d}{ }^{2}}+I_{r}-\frac{\left(I_{s 1}+I_{g}\right)}{\rho_{1}^{2}}-\frac{\left(I_{s 2}+I_{m}\right)}{\rho_{2}{ }^{2}}\right\} \dot{\omega}_{r}=\frac{T_{g}}{\rho_{1}}+\frac{T_{m}}{\rho_{2}}-\frac{T_{w}}{G_{d}}
$$

where $m$ is the mass of vehicle in $\mathrm{kg}, \quad r$ is the radius of the wheels in meters, $G_{d}$ is the gear ratio between the wheels and ring gear. The term $\frac{m r^{2}}{G_{d}{ }^{2}}$ is vehicle inertia acting on the ring gear. $I_{r}$ is ring inertia. As the angular velocities of ring, MG2 and 
MG1 are related by (Eq.6), a single equation is sufficient to get the wheel velocity, and source angular velocities.

\subsubsection{Hybrid Mode}

As the clutch of carrier is disengaged from ground, the carrier can experience force exerted by both motors. This exerted force also helps in starting the engine and driving it to idling speed. As soon as engine reaches idling speed and switches to power mode, vehicle switches to hybrid mode. In hybrid mode, all the three units of planetary gear set are connected. The dynamics of MG2 remains same while that of MG1 would change. Since engine is connected to carrier, the dynamics of the engine is added to the group of equations developed for EV mode. Figure 3.13 shows the power split device in hybrid mode. Green arrows indicate that power is given to the vehicle and red arrows indicate that electrical power is generated by MG1.

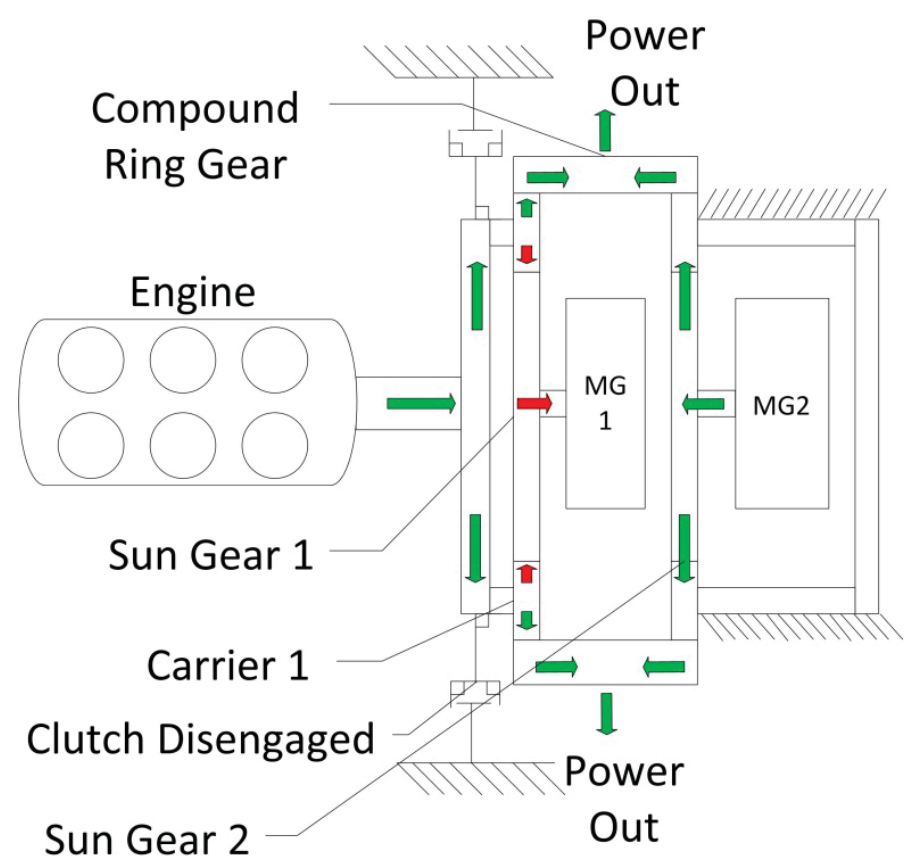

Figure 3.13: Power-split powertrain in hybrid mode

\subsubsection{Engine Dynamics in Hybrid Mode}

Assume that engine provides a torque in clockwise direction. The torques experienced by engine is shown in Figure 3.14 with free body diagram at engine shaft. The dynamics of engine can be given by Eq. 12 . 


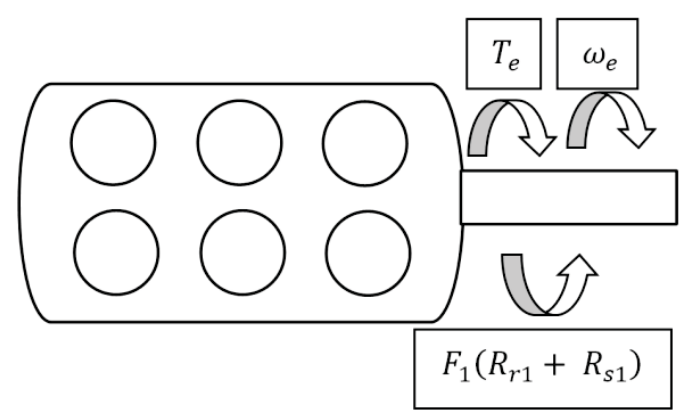

Figure 3.14: Free body Diagram of engine connected to carrier

$$
\left(I_{e}+I_{c 1}\right) \dot{\omega}_{e}=T_{e}-F_{1}\left(R_{r 1}+R_{s 1}\right)
$$

\subsubsection{MG1 Dynamics in Hybrid Mode}

The dynamics of MGI changes as it is acting as a generator absorbing part of engine torque. The free body diagram of MG1 shown in the Figure 3.15 is used to form the dynamic equation

$$
\begin{gathered}
I_{g} \dot{\omega}_{g}=T_{s 1}+T_{g} \\
I_{g} \dot{\omega}_{g}=F_{1} \cdot R_{s 1}+T_{g}
\end{gathered}
$$

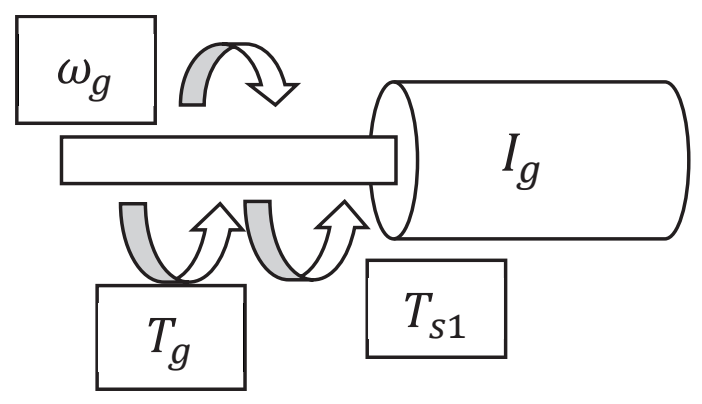

Figure 3.15: Free body diagram of MG1 in hybrid mode

Eq. 1 mentioned before is for a simple planetary gear set. The equation can be modified to get relation between the angular velocities of MG1, MG2 and engine for THS III. The new equation is obtained by substituting $\omega_{r}=-\omega_{m} \rho_{2}$ in Eq. 1 as shown in Eq. 15. 


$$
\omega_{g}=\left(\frac{1+\rho_{1}}{\rho_{1}}\right) \cdot \omega_{e}+\omega_{m}\left(\frac{\rho_{2}}{\rho_{1}}\right)
$$

Differentiating Eq. 15 and substituting into Eq. 14 gives the new value of $F_{1}$ for hybrid mode.

$$
F_{1}=\frac{\left(I_{S 1}+I_{g}\right)\left(\frac{1+\rho_{1}}{\rho_{1}}\right) \dot{\omega}_{e}+\dot{\omega}_{m}\left(\frac{\rho_{2}}{\rho_{1}}\right)-T_{g}}{R_{S 1}}
$$

Substituting $F_{1}$ value into Eq. 12 gives Eq. 17.

$$
\left\{\left(I_{e}+I_{c}\right)+\left(I_{s 1}+I_{g}\right)\left(\frac{1+\rho_{1}}{\rho_{1}}\right)^{2}\right\} \dot{\omega}_{e}+\left\{\left(I_{s 1}+I_{g}\right)\left(\frac{1+\rho_{1}}{\rho_{1}}\right)\right\} \dot{\omega}_{m}\left(\frac{\rho_{2}}{\rho_{1}}\right)=T_{e}+T_{g}\left(\frac{1+\rho_{1}}{\rho_{1}}\right)
$$

This gives one equation in terms of engine angular acceleration and MG2 angular acceleration. To solve 2 unknowns, the value of $F_{1}$ and $F_{2}$ are substituted into ring dynamic equation in Eq. 3. $F_{2}$ value will be similar to the value calculated in EV mode as the carrier 2 is still grounded and MG2 is acting as motor. After substitution and let $T_{r}=\frac{T_{w}}{G_{d}}, \quad \dot{\omega}_{r}=-\dot{\omega}_{m} \rho_{2}$, Eq. 3 becomes Eq.18.

$$
-\left\{\left(I_{s 1}+I_{g}\right)\left(\frac{1+\rho_{1}}{\rho_{1}}\right)\right\} \dot{\omega}_{e}-\left\{\frac{m r^{2}}{G_{d}{ }^{2}}+I_{r}-\frac{\left(I_{s 1}+I_{g}\right)}{\rho_{1}{ }^{2}}-\frac{\left(I_{s 2}+I_{m}\right)}{\rho_{2}{ }^{2}}\right\} \dot{\omega}_{m} \rho_{2}=-\frac{T_{g}}{\rho_{1}}+\frac{T_{m}}{\rho_{2}}-\frac{T_{w}}{G_{d}}
$$

Eq. 18

Based on Eq.17 and Eq.18, the state space model in matrix form can be created as shown in Eq. 19.

$$
\begin{aligned}
& {\left[\begin{array}{cc}
\left\{\left(I_{e}+I_{c}\right)+\left(I_{s 1}+I_{g}\right)\left(\frac{1+\rho_{1}}{\rho_{1}}\right)^{2}\right\} & \left\{\left(I_{s 1}+I_{g}\right)\left(\frac{1+\rho_{1}}{\rho_{1}}\right)\right\}\left(\frac{\rho_{2}}{\rho_{1}}\right) \\
-\left\{\left(I_{s 1}+I_{g}\right)\left(\frac{1+\rho_{1}}{\rho_{1}}\right)\right\} & -\left\{\frac{m r^{2}}{G_{d}{ }^{2}}+I_{r}-\frac{\left(I_{s 1}+I_{g}\right)}{\rho_{1}{ }^{2}}-\frac{\left(I_{s 2}+I_{m}\right)}{\rho_{2}{ }^{2}}\right\} \rho_{2}
\end{array}\right]\left[\begin{array}{c}
\dot{\omega}_{e} \\
\omega_{m}
\end{array}\right]=} \\
& {\left[\begin{array}{cccc}
1 & \left(\frac{1+\rho_{1}}{\rho_{1}}\right) & 0 & 0 \\
0 & -\frac{1}{\rho_{1}} & \frac{1}{\rho_{2}} & -\frac{1}{G_{d}}
\end{array}\right]\left[\begin{array}{c}
T_{e} \\
T_{g} \\
T_{m} \\
T_{w}
\end{array}\right]}
\end{aligned}
$$

The equation Eq.19 is of $\alpha \dot{X}=\beta U$ form which can be written as $\dot{X}=\alpha^{-1} \beta U$. The complete state equation is written as Eq. 20. 


$$
\begin{aligned}
& {\left[\begin{array}{c}
\dot{\omega_{e}} \\
\dot{\omega_{m}}
\end{array}\right]=\left[\begin{array}{ll}
0 & 0 \\
0 & 0
\end{array}\right]\left[\begin{array}{l}
\omega_{e} \\
\omega_{m}
\end{array}\right] } \\
&+\left[\begin{array}{cc}
\left\{\left(I_{e}+I_{c}\right)+\left(I_{s 1}+I_{g}\right)\left(\frac{1+\rho_{1}}{\rho_{1}}\right)^{2}\right\} & \left\{\left(I_{s 1}+I_{g}\right)\left(\frac{1+\rho_{1}}{\rho_{1}}\right)\right\}\left(\frac{\rho_{2}}{\rho_{1}}\right) \\
-\left\{\left(I_{s 1}+I_{g}\right)\left(\frac{1+\rho_{1}}{\rho_{1}}\right)\right\} & -\left\{\frac{m r^{2}}{G_{d}{ }^{2}}+I_{r}-\frac{\left(I_{s 1}+I_{g}\right)}{\rho_{1}{ }^{2}}-\frac{\left(I_{s 2}+I_{m}\right)}{\rho_{2}{ }^{2}}\right\} \rho_{2}
\end{array}\right]^{-1} *
\end{aligned}
$$$$
\left[\begin{array}{cccc}
1 & \left(\frac{1+\rho_{1}}{\rho_{1}}\right) & 0 & 0 \\
0 & -\frac{1}{\rho_{1}} & \frac{1}{\rho_{2}} & -\frac{1}{G_{d}}
\end{array}\right]\left[\begin{array}{c}
T_{e} \\
T_{g} \\
T_{m} \\
T_{w}
\end{array}\right]
$$

If the output vector is selected the same as state vector, the output equation for the state space model would be Eq. 21.

$$
\left[\begin{array}{c}
\omega_{e} \\
\omega_{m}
\end{array}\right]=\left[\begin{array}{ll}
1 & 0 \\
0 & 1
\end{array}\right]\left[\begin{array}{l}
\omega_{e} \\
\omega_{m}
\end{array}\right]+\left[\begin{array}{llll}
0 & 0 & 0 & 0 \\
0 & 0 & 0 & 0
\end{array}\right]\left[\begin{array}{c}
T_{e} \\
T_{g} \\
T_{m} \\
T_{w}
\end{array}\right]
$$

The output of $\omega_{e}$ and $\omega_{m}$ in hybrid mode can be found by solving this state equation. The angular velocity of wheels $\omega_{\text {wheel }}$, can be found using reduction ratio $G_{d}$. While the angular velocity of the generator, $\omega_{g}$, can be found using Eq. 15 . 


\section{HIL SIMULATION VEHICLE MODEL}

\subsection{Overview of Vehicle Model}

The vehicle plant model for the power-split HEV was built based on a parallel vehicle model provide by dSPACE Inc. The vehicle plant model can be classified into four categories.

SoftECUs: contains all the ECUs in soft model and all the decision making algorithms.

The Plant: has all the vehicle and subsystem level models to act precisely as vehicle and its subsystems.

The Sensors and Actuators: has all real time interface blocks needed to simulate and detect incoming and outgoing signals.

The Environment: simulate the driver and its response, road condition, gear selections Accelerator Pedal Position (APP) and Brake Pedal Position (BPP).

Figure 4.1 gives the overview of the vehicle model developed in Simulink environment. 


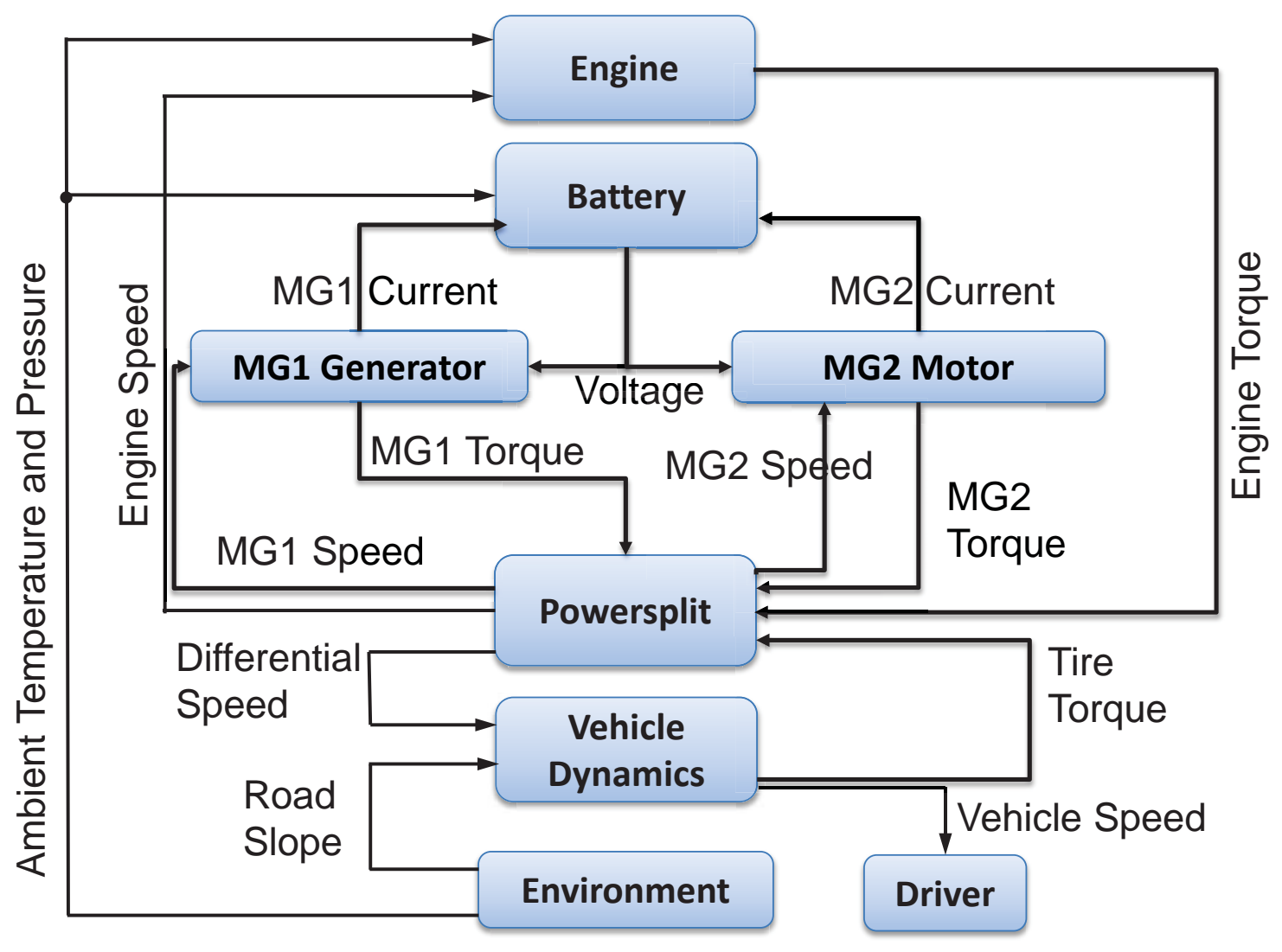

Figure 4.1: Overview of the vehicle model 


\subsection{Vehicle ECU Network}

ECU is the brain of the vehicle which is involved in every decision making process. The vehicle ECU network is structured to two levels of control. The higher level is Hybrid Vehicle Controller (HVC). The lower level is gasoline engine controller and motor controllers. The HVC level is the prime decision making level. HVC subsystem is divided into "Hybrid mode on/off," "Brake control," "Torque request coordination," "ICE start/stop," "Clutch control" and "Drive management."

"Hybrid mode on/off" decides whether the vehicle is to be driven in EV mode or HEV mode. "Brake control" decides the amount of brake energy to be regenerated using MG2 while the rest being passed on to friction brakes. The "Torque request coordination" is calibrated as per APP and maximum torque curve of MG2 and engine. The "Clutch control" is a simple model which works with "Drive management" and vehicle mode selection. The clutch is used to ground engine carrier arm. The clutch is engaged when vehicle is to be run in EV mode. "Drive management" is a crucial subsystem which decides the vehicle mode selection, engine mode selection and the distribution of the torque based on these modes. The vehicle plant model is designed to be EV/HEV. The vehicle has two modes with planetary gear set at its core. The first mode is the Electric only (EV) mode and the second mode is power-split HEV mode. ICE has 3 modes, (1) off (2) idle and (3) power mode. All these modes are controlled by a Stateflow control algorithm.

Figure 4.2 shows the control algorithm for mode selection process. The model was divided into four blocks. Vehicle starts with engine off (ICE mode=0) and electric only mode on (vehicle mode $=0$ ). If the torque request is greater than 0 as well as the State Of Charge (SOC) is lower than SOC lower limit (60\%), mode selection switches to ICE mode=1. This is ICE idling mode. The clutch is released to start the engine. Vehicle goes to hybrid mode $=1$ only when vehicle speed is greater than $20 \mathrm{mph}$. This is because the engine operates in very high BSFC region at low rpm, which gives overall low efficiency. Engine can also be in power mode if SOC falls below SOC_emg along with battery temperature conditions for safety reasons. SOC_emg is very low SOC region and battery needs to be charged immediately. If 
battery temperature fall out of safe operating region $\left(0^{\circ} \mathrm{C}<\right.$ battery temperature $<80^{\circ} \mathrm{C}$ ), the engine provides traction power.

If the torque request falls below 0 , vehicle is braking. The engine changes to idling mode and the vehicle changes to electric mode. If braking time is longer than 1 second, the clutch is engaged, engine is turned off, and MG1 along with MG2 provide regenerative braking. If engine charges battery to the upper limit and battery temperature is within operating limits, engine stops and both electric motors provide required torque. Vehicle operates in electric only mode.

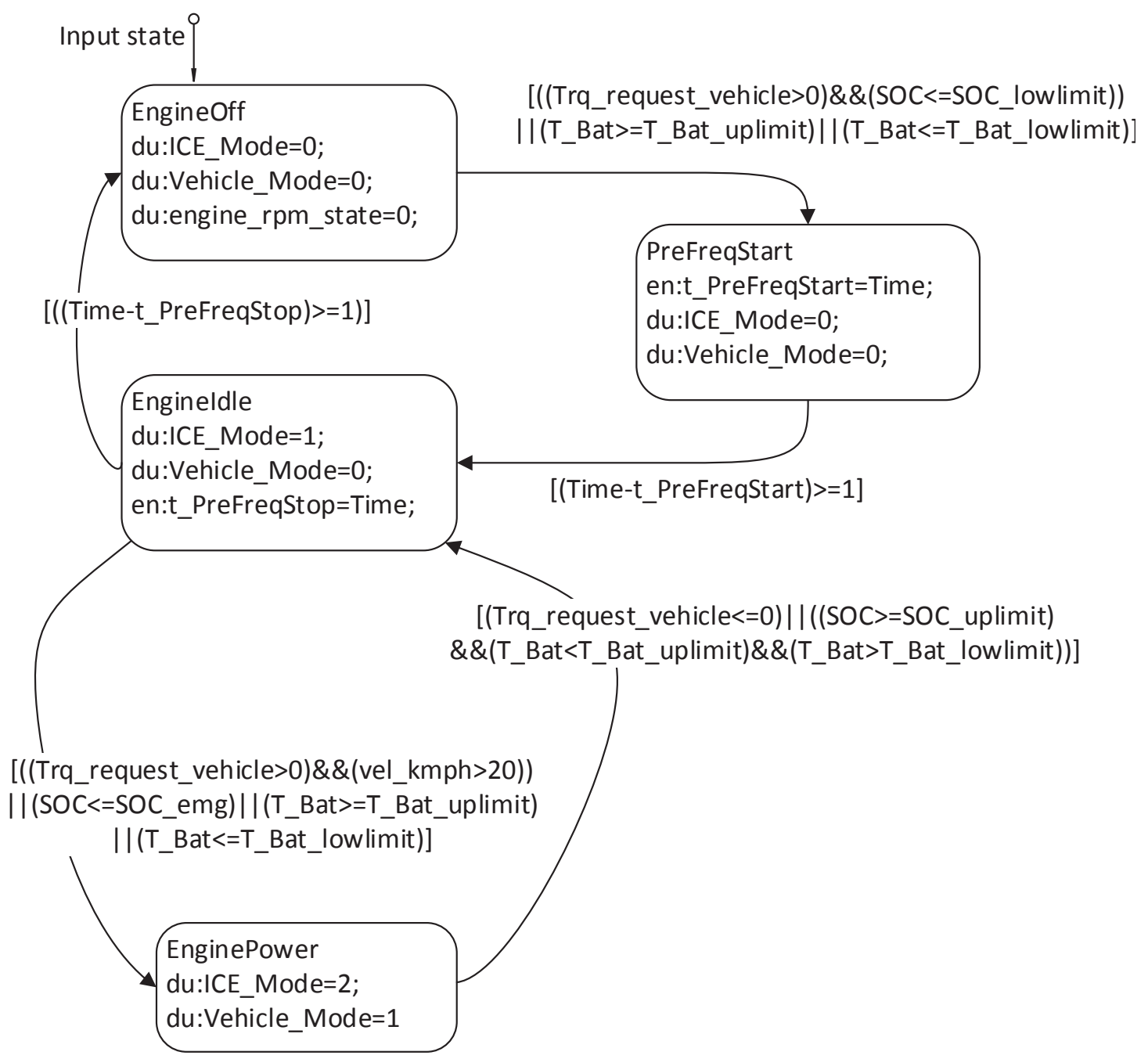

Figure 4.2: Control strategy to select vehicle mode 
The torque request distribution was done in both modes. In electric mode, as clutch is engaged and carrier 1 is locked, MG1 along with MG2 can produce torque to propel the vehicle. The torque request was distributed to ratio of $M G 2: M G 1=1: 1$ as both the motors are of equal rating and the gear ratio are equal. While starting the engine, MG1 is starting motor as well. MG1 has to produce torque in clockwise direction. As soon as the ICE mode changes to idling, the MG2 has to provide the entire torque request. MG1 compensates the engine speed with respect to vehicle speed so that engine idling speed of $800 \mathrm{rpm}$ is maintained.

In hybrid mode, torque split is decided on rule-based control algorithm. The RPM of engine decides the torque of engine and is limited by the maximum MG1 RPM as well as current vehicle speed as per equation Eq.15. The purpose of hybrid mode is to recharge battery while operating engine in optimum range to get maximum fuel efficiency for given condition. For hybrid mode torque distribution, power request from drivers is split into engine power request and MG2 motor power request. The split ratio is determined based on current SOC of battery using a lookup table. Engine provides most power at low SOC while charge sustaining. Once the power is split, engine speed is decided from a look-up table containing optimum power to speed curve. The speed from loop-up table divides power request for engine to give engine torque request. The e-motor rpm coming from MG2 motor divides its power request to give motor torque request. In hybrid mode, engine operates in two states, battery charge sustaining and battery charging. In charge sustaining state, engine provides torque to the wheels completely via electrical and mechanical path. In mechanical path the torque is provided through the gears of power-split device and reduction device. In electrical path, torque goes through MGI generated and is provided to MG2 for propulsion. Thus, very low or no power is provided by the battery in charge sustaining mode. In charging mode, the engine provides excess power so that the torque requirement for mechanical and electrical path is fulfilled along with battery SOC build-up. In summary, the power of the battery is controlled in three states: charge depletion state in electric only mode, charge sustaining and charging state in hybrid mode of vehicle. 
The Engine Control Unit (ECU) and MG1/MG2 controllers are at second level. Engine control unit used in this case of HIL simulation was a SoftECU. The engine SoftECU is provided by dSPACE. The ECU is presented in ASM library of dSPACE. It is used to decide the injection pressure, mass of fuel, mass of induced air, turbocharger pressure, EGR control, throttle position and various other parameters for engine plant model. DS2211 board is used to simulate the sensor and actuator signals. The various blocks needed for the interface can be found in dSPACE library.

The MG1 controller is a softECU used to control MG1 while MG2 controller is a hardware ECU built in MicroAutoBox. MG1 and MG2 controllers are used to control their respective motors on the basis of torque request calculated by hybrid ECU in electric only mode. In hybrid mode, MG2 is controlled with torque request as it is the primary motor while MGI is controlled by engine RPM request as its primary function is to compensate the engine RPM with respect to vehicle speed. 


\subsection{Vehicle Plant Model}

The plant model of the vehicle has a gasoline engine, 2 Permanent Magnet Synchronous Motors (PMSM), a power-split drive train, a battery model, vehicle dynamics model and environment subsystem. Figure 4.3 shows the architecture of the vehicle.

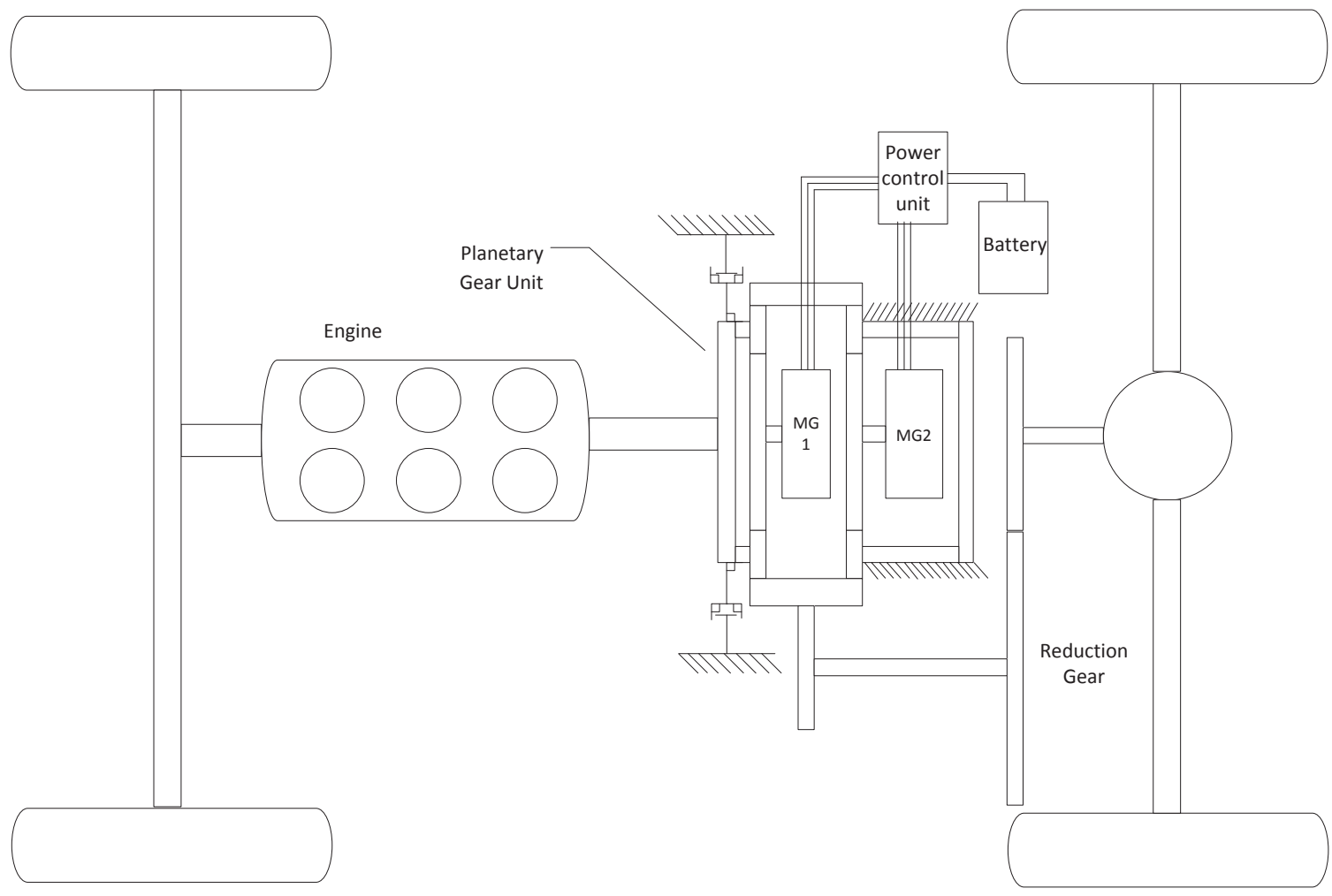

Figure 4.3: Vehicle architecture

\subsubsection{Engine Model}

A 2.9 liter, 6 cylinders engine is modeled in Simulink platform. The model is divided into 5 subsystems as shown in Figure 4.4. "Fuel system" controls all the fuel pump, fuel metering, and injection pressure. "Air path" has intake and exhaust manifold along with EGR and turbocharger. The "Piston engine" has the cylinder inlet, torque generated due to combustion. Finally, the "Coolant subsystem" and "Exhaust subsystem" deal with engine cooling and exhaust emissions. The engine model, 
designed by dSPACE, is equipped with turbocharger and EGR. For the power-split vehicle, the engine was equipped with just EGR. Turbocharger was kept off.

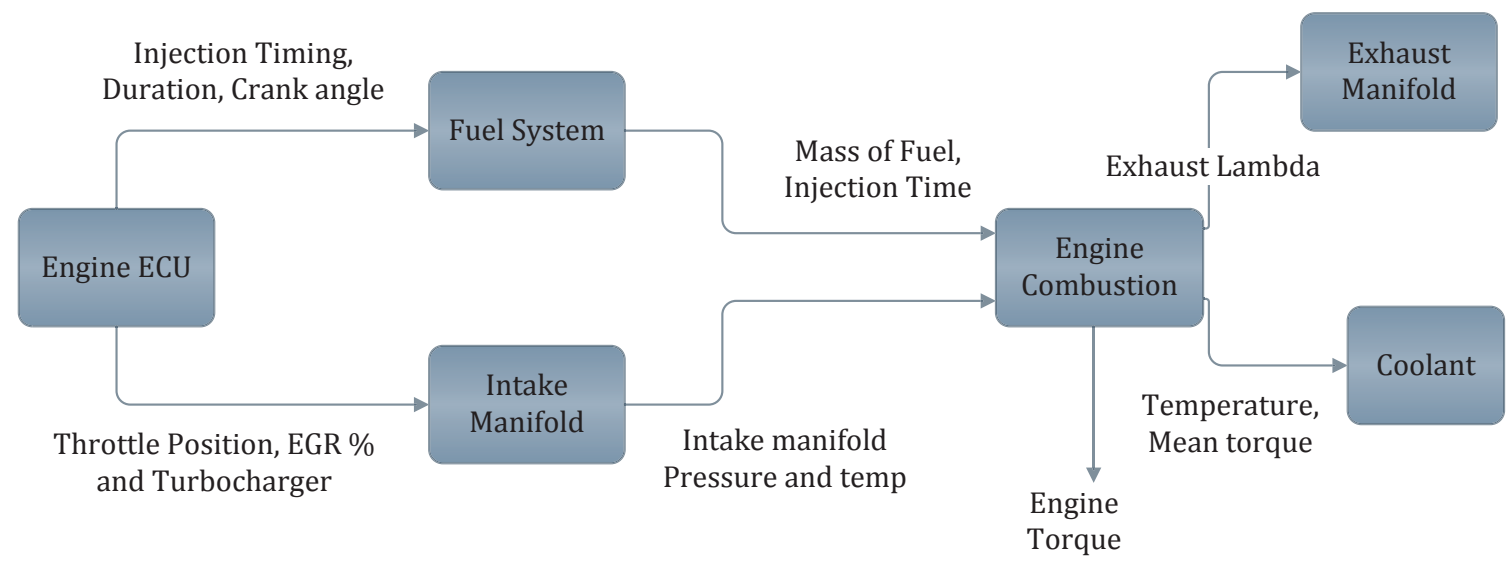

Figure 4.4: dSPACE engine model

\subsubsection{Model of Electronic Components}

\subsubsection{Motor Model}

The planetary gear set of hybrid synergy drive train has two motors attached to two sun gears. The MG1 attached to sun gear 1 and the MG 2 is attached to sun gear 2 . The motors selected for this hybrid vehicle are two $43 \mathrm{kw}$ Permanent Magnet Synchronous Motors. Motor is selected on the basis of its high efficiency and high torque performance. Figure 4.5 shows motor efficiency map. Mathematical model for motors is given by Eq.23-25 [16]

$$
\begin{aligned}
& L_{d} \frac{d i_{d}}{d t}=v_{d}-R_{s} i_{d}+L_{d} \omega_{e} i_{q} \\
& L_{q} \frac{d i_{q}}{d t}=v_{q}-R_{s} i_{q}+L_{q} \omega_{e} i_{d}-\psi_{p} \omega_{e} \\
& \operatorname{Trq}=\frac{3}{2} p\left[\psi_{p} i_{q}+\left(L_{d}-L_{q}\right) i_{q} i_{d}\right]
\end{aligned}
$$

where $L_{d}$ and $L_{q}$ are inductance along $\mathrm{d}$-axis and $\mathrm{q}$ axis of reference. $v_{d}$ and $v_{q}$ are voltage along $\mathrm{d}$-axis and $\mathrm{q}$ axis of reference. $i_{d}$ and $i_{q}$ are current in $\mathrm{d}$-axis and $\mathrm{q}$ axis of reference. $R_{s}$ is stator resistance. $\omega_{e}$ is the angular velocity of motor, $\psi_{p}$ is the flux induced by permanent magnet. $p$ is the number of poles. 


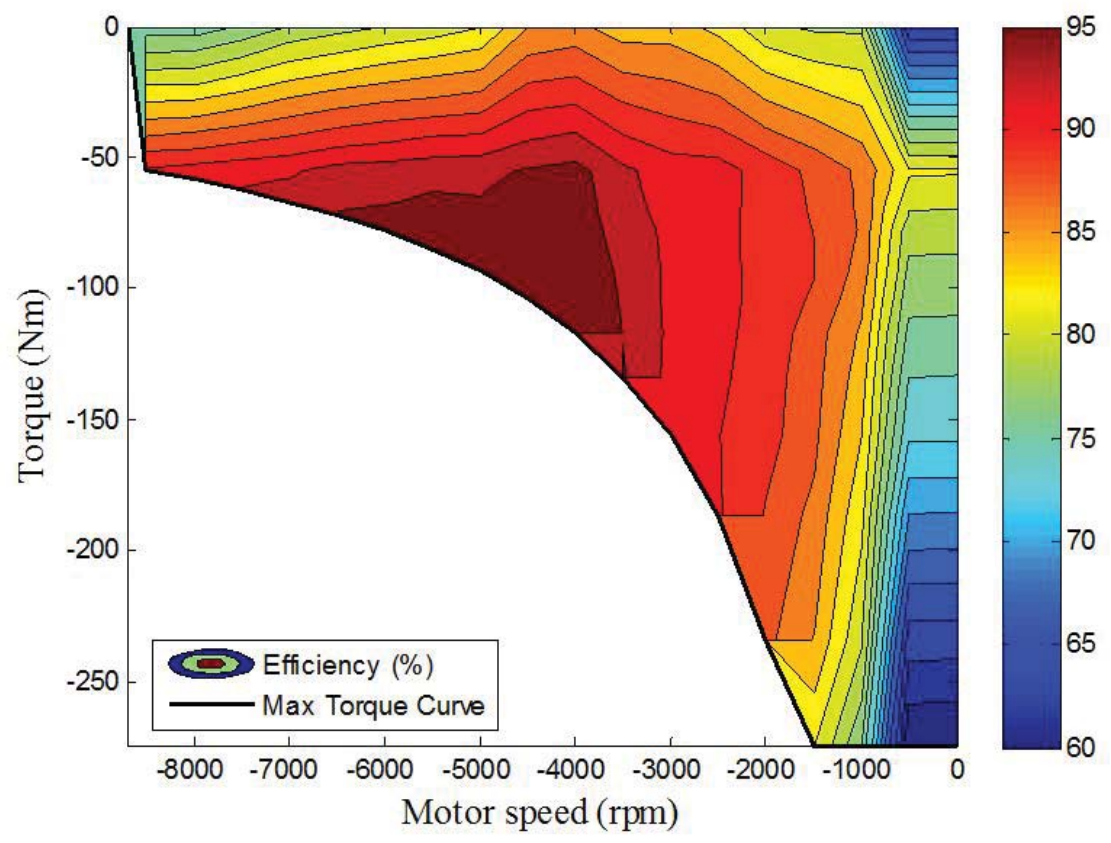

Figure 4.5: MG2 and MG1 motor efficiency map

Figure 4.6 shows the block diagram of electric component model. A PMSM motor needs three-phase current for its coils to generate the required torque. The threephase current is generated by a three-phase inverter. For this project, IGBT switches are used in the three-phase conversion process of inverter. The Pulse Width Modulation (PWM) signal coming from motor controller is used to control three-phase inverter. The duty cycle of the PWM signal decides the amount of current to be sent to motors. By controlling the duty cycle, the speed of PMSM motor is controlled. 


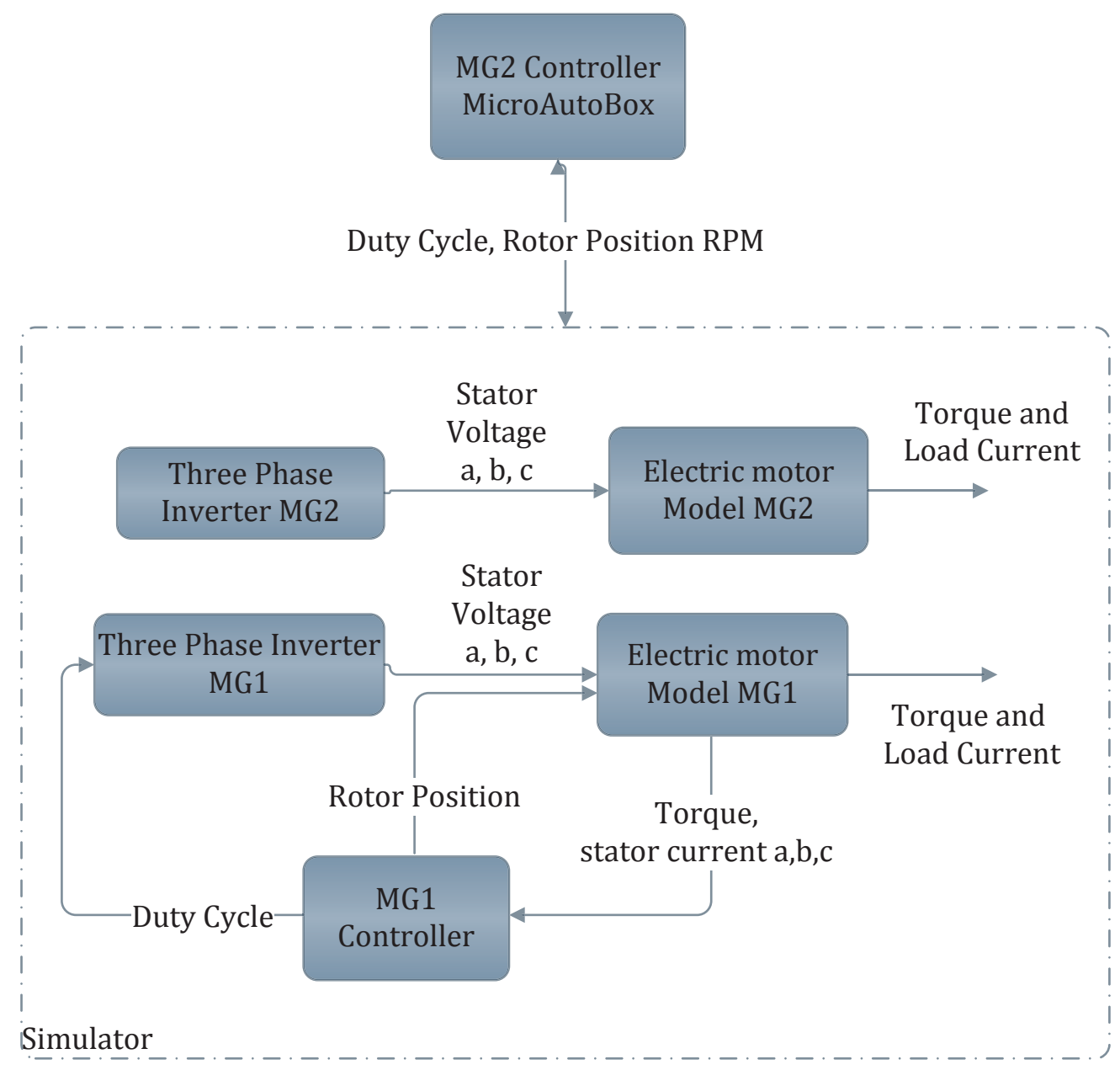

Figure 4.6: dSPACE electric components model

The MG2 motor is controlled using MicroAutobox in dSPACE HIL environment. The plant model sends motor RPM, three-phase current to the controller and motor torque request is send by hybrid ECU. The MG1 plant model is similar to MG2 plant model in all aspects as the motor specifications are same. The controller for MG1 used is a soft controller. The MG1 controller is very similar to MG2 controller. However, MG1 controller is implemented with plant model in dSPACE simulator not in MicroAutoBox.

The vehicle speed control is based on MG2 speed control and the compensatory speed developed by MG1 for engine speed variation. As vehicle does not have any automatic or manual transmission, MG1 speed variation is very crucial. This allows the engine to be used at any speed irrespective of vehicle speed but limited by the 
MGI's maximum speed in both directions. Control of vehicle is done by controlling the MG1 speed in Hybrid mode. The MG2 motor is controlled using current control method which is proportional to torque generated by motor.

For both motors, the controller was borrowed from the ASM library of dSPACE software module. Controller used is a simple PI controller to control a motor in 3 operating modes (1) speed control, (2) current control and (3) voltage control. In current control mode, torque request is converted to q-axis current and is controlled by a PI controller. While in speed control, the RPM is converted to q-axis current and then controlled by the PI controller. This model is developed by the dSPACE Inc. The controller works in Clark and Park transformation, where $I_{d}$ and $I_{q}$ current/voltage are controlled in d-q axis. The transformation is shown in Eq. 26.

$$
\left[\begin{array}{c}
I_{d} \\
I_{q} \\
0
\end{array}\right]=\frac{2}{3}\left[\begin{array}{ccc}
\cos \theta & \cos \left(\theta-\frac{2 \pi}{3}\right) & \cos \left(\theta+\frac{2 \pi}{3}\right) \\
\sin \theta & \sin \left(\theta-\frac{2 \pi}{3}\right) & \sin \left(\theta+\frac{2 \pi}{3}\right) \\
0.5 & 0.5 & 0.5
\end{array}\right]\left[\begin{array}{c}
I_{a} \\
I_{b} \\
I_{c}
\end{array}\right]
$$

The primary role of MG1 is to act as a speeder in hybrid mode of vehicle. The angular velocity of motor is used to keep the speed of engine at optimum level so as to get maximum efficiency over a drive cycle. But MGI also acts as a load motor in EV mode which is controlled in current control mode. The transition of the current control to speed control takes place in EV mode of vehicle. Here, the engine can be in idling and clutch is disengaged. When engine is to be started, MG1 provides the necessary torque along with MG2 in speed control mode. MG2 provides complete torque to vehicle to fulfill the torque request. The MG1 controller only works as current controller when engine is off. The Hybrid ECU decides which mode the controller must act so as to get maximum efficiency of the vehicle. 


\subsubsection{Battery Model}

The battery model was borrowed from ASM library of dSPACE Inc. The model consists of maximum 100 cells with rating of the module as shown in the Table 2.

Table 2: Battery Specification

\begin{tabular}{|c|c|}
\hline \multicolumn{2}{|c|}{ Battery Specs } \\
\hline Type & Li-ion \\
\hline Number of cells & 100 \\
\hline Voltage & $360 \mathrm{~V}$ \\
\hline Peak Current & 250A \\
\hline
\end{tabular}

The battery management for two motors was added to the battery subsystem. As both MG2 and MG1 are used as motor and generator, the right connection between the outputs of MG2 and MG1 can save the SOC for future need of drive cycle. In Hybrid mode, the MG1 acts as a generator while the MG2 is a motor drawing the current from battery. The motor current is three-phase so the load current is calculated by summing three phases. The three-phase current is provided by a three-phase inverter and is directed towards battery to calculate battery current. The load current of motor MG2 varies with torque requested. The forward modeling of battery has voltage as output and motor current as input. The battery current can be manipulated by simple addition of currents as per the equation Eq. 22. This addition allows MG1 generated current to be sent to MG2 motor and remaining can be sent to battery for its sustainability. So, the addition decides the battery current $I_{b a t}$ and the SOC is affected based on the addition of current.

$$
I_{b a t}=I_{M G 2}+I_{M G 1}
$$




\subsubsection{Development of Power-split Drivetrain Model}

The power-split drive train was newly modeled for this vehicle. A modified THS III was considered for power-split HEV HIL simulation. 2010 Prius has synergy drive (THS III) built into it. The modeled drive train has 2 planetary gear set configurations as mentioned earlier. Three components, i.e. the sun-1 carrier-1 and sun-2, are powered by MG1, gasoline engine, and MG2, respectively.

The model developed in Simulink was based on the equations developed in section 3. The dynamics of engine, MG1 and MG2 was included in to the dynamics of powersplit device. Hence, no dynamic models for engine or motors were needed. The torque signals coming from engine, MG2, MG1 and the vehicle resistance coming from vehicle dynamics are given as inputs to the EV mode block and hybrid mode block as shown in Figure 4.7.

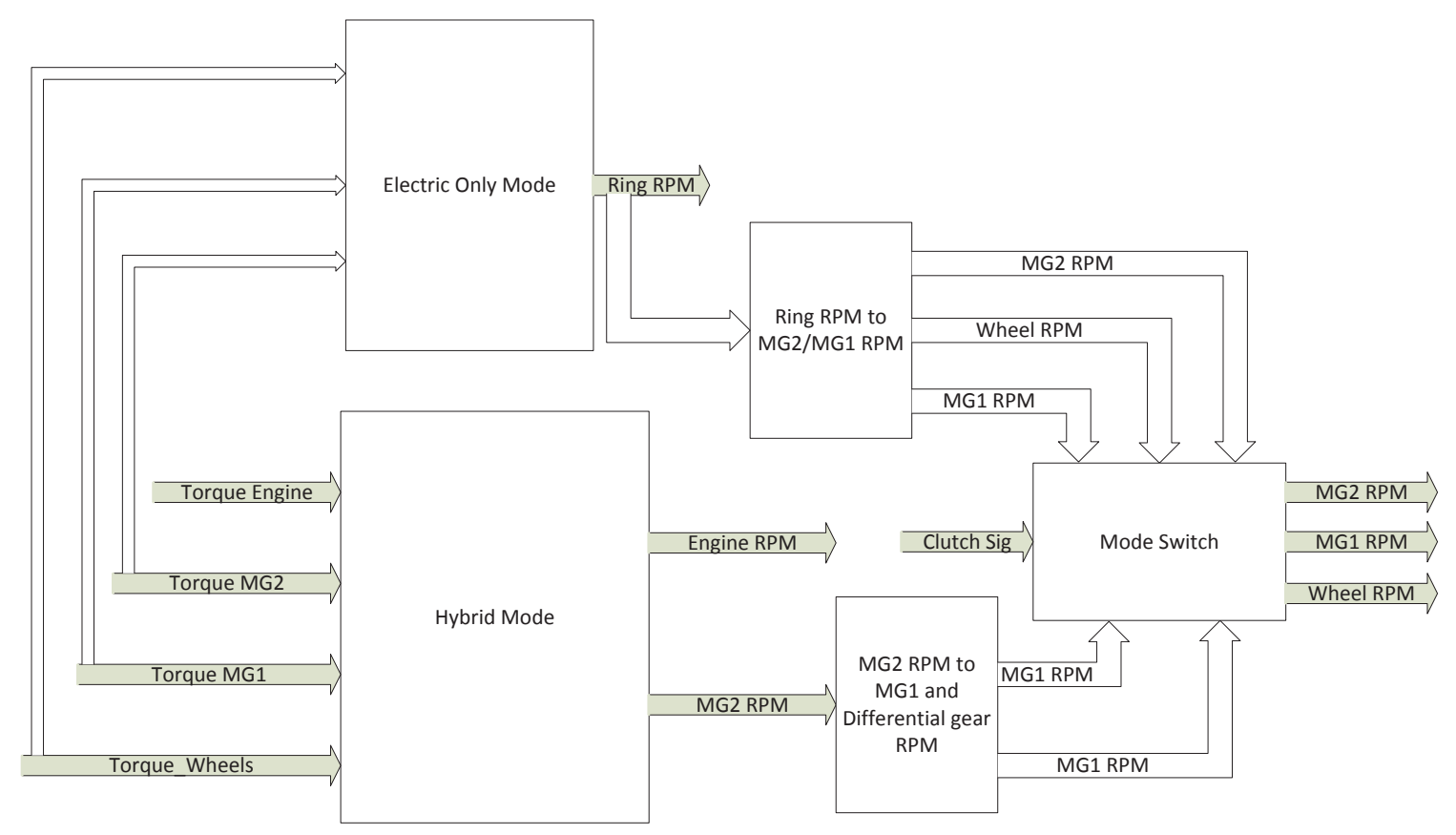

Figure 4.7: Power-split model 
The equations needed for simulation of electric and hybrid modes are of discrete forms as the simulator works at sample rate of $T_{S}=0.001$ seconds. So, the model is executed for each time step of 0.001 seconds. For electric only mode equation, Eq.11 has one variable, angular acceleration of ring. This has been solved by division of torque and inertia as shown in equation Eq.27

$$
\frac{\omega_{r}(k)-\omega_{r}(k-1)}{T_{S}}=\frac{-\frac{T_{g}(k)}{\rho_{1}}-\frac{T_{m}(k)}{\rho_{2}}-\frac{T_{W}(k)}{G_{d}}}{\left\{\frac{m r^{2}}{G_{d}{ }^{2}}+I_{r}-\frac{\left(I_{S 1}+I_{g}\right)}{\rho_{1}{ }^{2}}-\frac{\left(I_{S 2}+I_{m}\right)}{\rho_{2}{ }^{2}}\right\}}
$$

where $\mathrm{k}$ is the discrete time step. Three input variables, torque of MGl $T_{g}(k)$, torque of MG2 $T_{m}(k)$ and reaction torque from wheels $T_{w}(k)$ in discrete form, were used to calculate angular acceleration of ring $\dot{\omega}_{r}(k)$. Torque values from MG2 and MG1 are negative as the torque is generated in $3^{\text {rd }}$ quadrant of PMSM map. Hence, the signs of MG2 and MG1 torque in Eq.27 are negative so that the resultant torque of ring is positive and $\dot{\omega}_{r}(k)$ is positive. For electric only mode, the angular velocities of MG1 and MG2 are related to the RPM of wheel by gear ratios $\rho_{1}, \rho_{2}$ and $G_{d}$. The values of $\omega_{g}(k), \omega_{m}(k)$ and $\omega_{w}(k)$ were calculated by Eq.28, Eq.29 and Eq.30.

$$
\begin{aligned}
& \omega_{g}(k)=\frac{-\omega_{r}(k)}{\rho_{1}} \\
& \omega_{m}(k)=\frac{-\omega_{r}(k)}{\rho_{2}} \\
& \omega_{w}(k)=\frac{\omega_{r}(k)}{G_{d}}
\end{aligned}
$$

For hybrid mode, Eq.17 and Eq.18 have two variables. They are angular acceleration of engine and angular acceleration of MG2. Eq. 17 and Eq. 18 are in continuous form. They are converted to discrete form as shown in Eq. 33 and Eq. 34.

$$
\begin{aligned}
\left\{\left(I_{e}+I_{c}\right)+\left(I_{s 1}\right.\right. & \left.\left.+I_{g}\right)\left(\frac{1+\rho_{1}}{\rho_{1}}\right)^{2}\right\} \times \frac{\left(\omega_{e}(k)-\omega_{e}(k-1)\right)}{T_{s}}+\left\{\left(I_{s 1}+I_{g}\right)\left(\frac{1+\rho_{1}}{\rho_{1}}\right)\right\} \times\left(\frac{\rho_{2}}{\rho_{1}}\right) \\
& \times \frac{\left(\omega_{m}(k)-\omega_{m}(k-1)\right)}{T_{s}}
\end{aligned}
$$




$$
\begin{gathered}
=T_{e}(k)+T_{g}(k) \times\left(\frac{1+\rho_{1}}{\rho_{1}}\right) \\
-\left\{\left(I_{s 1}+I_{g}\right)\left(\frac{1+\rho_{1}}{\rho_{1}}\right)\right\} \times \frac{\left(\omega_{e}(k)-\omega_{e}(k-1)\right)}{T_{s}}-\left\{\frac{m r^{2}}{G_{d}{ }^{2}}+I_{r}+\frac{\left(I_{s 1}+I_{g}\right)}{\rho_{1}{ }^{2}}+\frac{\left(I_{s 2}+I_{m}\right)}{\rho_{2}{ }^{2}}\right\} \times \rho_{2} \\
\quad \times \frac{\left(\omega_{m}(k)-\omega_{m}(k-1)\right)}{T_{s}}
\end{gathered}
$$$$
=-\frac{T_{g}(k)}{\rho_{1}}-\frac{T_{m}(k)}{\rho_{2}}-\frac{T_{w}(k)}{G_{d}}
$$

For hybrid mode the generator speed $\omega_{g}(k)$ is calculated by Eq. 35,

$$
\omega_{g}(k)=\left(\frac{1+\rho_{1}}{\rho_{1}}\right) \cdot \omega_{e}(k)+\omega_{m}(k)\left(\frac{\rho_{2}}{\rho_{1}}\right)
$$

whereas wheel RPM is calculated using Eq. 36

$$
\omega_{w}(k)=\frac{-\omega_{m}(k) * \rho_{2}}{G_{d}}
$$

All the RPM values calculated using Eq. 28 to Eq. 36 were used in the mode selection block as shown in Figure 4.7. The mode selection is done on the basis of clutch signal while clutch signal is decided on the basis of ICE mode. If ICE mode is in idling (ICE mode $=1$ ) or power $($ ICE mode $=2$ ), clutch is released from ground and carrier 1 is free to rotate. The change in vehicle mode was done with a multiport switch with clutch signal being switching signal. The output RPM values of MG2, MG1 and engine were sent as feedback to respective plant models. RPM value of wheel was used to calculate the vehicle velocity. 


\subsubsection{Vehicle Dynamics}

Vehicle dynamics model has all the resistive forces acting on wheels of vehicle. The vehicle experiences rolling resistance, aerodynamics drag, gradient resistance, brake force and tractive force as shown in Figure 4.8.

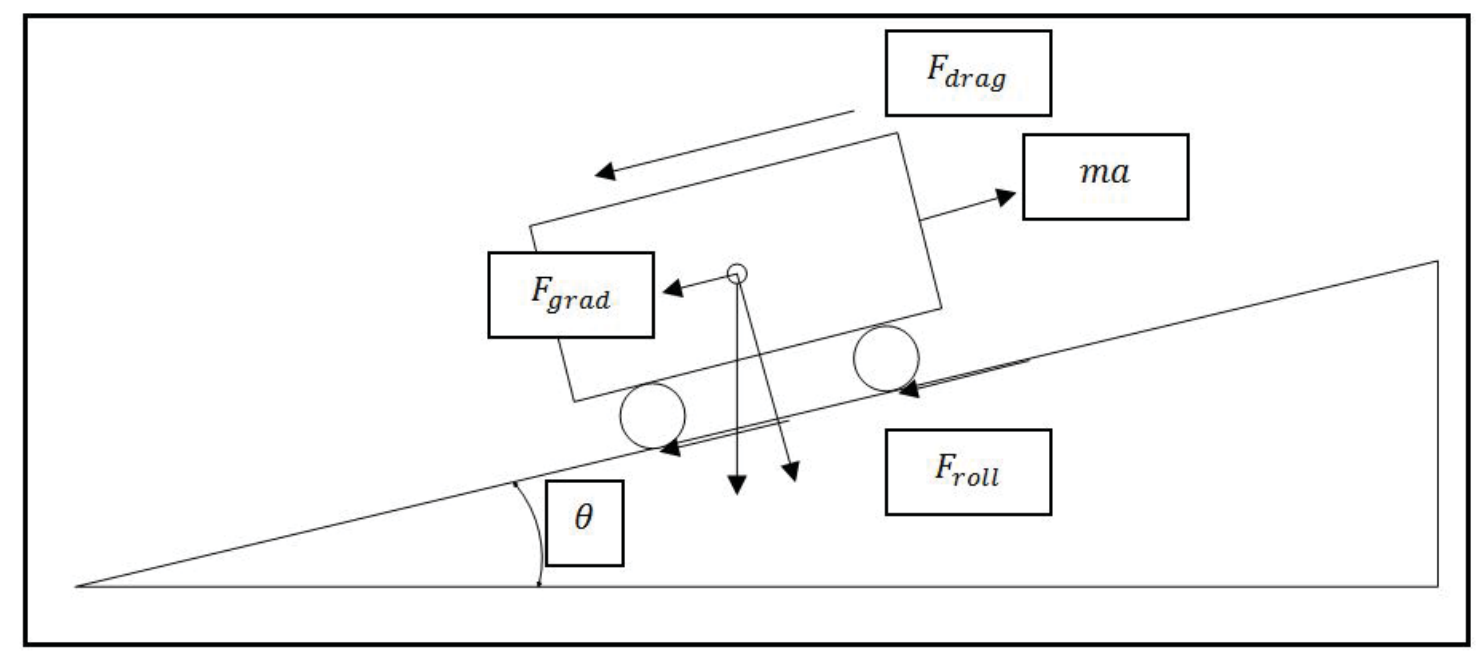

Figure 4.8: Vehicle dynamics

The rolling resistance acts due to rolling of the wheels. The rolling wheel has its own weight acting in downward direction which creates small deformation of the wheel. Ideally, a wheel should be touching the road surface tangentially with minimum surface contact. Due to surface contact, these wheels offer resistance to the movement in rotational direction. The rolling resistance is given by Eq. 37, where $m$ is the mass of vehicle in $\mathrm{kg}, \mathrm{g}$ is the acceleration due to gravity in $\mathrm{m} / \mathrm{s}^{2}, \theta$ is road gradient in degree, $f_{r}$ is friction factor.

$$
F_{\text {roll }}=m g \cos \theta f_{r}
$$

Aerodynamic drag is the fluidic resistance experienced by the vehicle when it passes through a medium. In the case of automobiles, the vehicle passes through the medium of air with density of $1.2 \mathrm{~kg} / \mathrm{m}^{3}$. The vehicle experiences a drag in opposite direction of vehicle movement. This drag can increase or decrease with the increase/decrease in wind velocity. For the simulation, the air as a medium was considered steady. The aerodynamic force is a function of cross sectional area of vehicle and the square of vehicle velocity as shown in Eq. 38, where $\rho$ is the density 
of air in $\mathrm{kg} / \mathrm{m3}, C_{d}$ is the coefficient of aerodynamic drag, $A$ is the cross sectional area in $\mathrm{m}^{2}, v$ is the velocity of vehicle in $\mathrm{m} / \mathrm{s}$.

$$
F_{\text {drag }}=\frac{1}{2} \rho C_{d} A v^{2}
$$

Third type of resistance experienced by the vehicle is the gradient resistance. This resistance is due to the road slope. The vehicle may be assisted or resisted depending on the direction of vehicle velocity and the slope. The weight of the vehicle helps in propelling the vehicle when velocity and slope are in same direction. The gradient resistance is a function of slope angle and vehicle weight given in Eq. 39. For the simulation, the slope was considered 0.

$$
F_{\text {grad }}=m g \sin \theta
$$

The traction force is the force coming from the powertrain of vehicle towards the wheels and is the only force propelling the vehicle in forward direction. For powersplit hybrid vehicle, there are three power sources, one engine and two electric motors. The brake force is the necessary force needed to stop the vehicle. A hybrid vehicle can apply brake force using the regenerative braking and friction brakes. In EV mode, both motors apply the regenerative brake while in hybrid mode just MG2 applies the regenerative brake. The friction brake is only applied when needed brake force is greater than the capacity of regenerative brakes.

The linear dynamics of the vehicle can be represented by Eq. 40. The parameter values used in simulation are given in Table 3.

$$
F_{T}=m a+m g \cos \theta f_{r}+\frac{1}{2} \rho C_{d} A v^{2}+m g \sin \theta
$$

Table 3: Constants used in simulation

\begin{tabular}{|l|l|l|}
\hline Sr. No. & Variable & Value \\
\hline 1 & Mass of vehicle in $\mathrm{kg}$ & 1250 \\
\hline 2 & friction factor & 0.01 \\
\hline 3 & density of air in $\mathrm{kg} / \mathrm{m}^{3}$ & 1.2 \\
\hline
\end{tabular}




\begin{tabular}{|l|l|l|}
\hline 4 & coefficient of aerodynamic drag & 0.35 \\
\hline 5 & cross sectional area in $\mathrm{m}^{2}$ & 2 \\
\hline 6 & Road gradient & 0 \\
\hline
\end{tabular}

\subsection{Sensors and Actuators}

The sensor and actuator interfaces are used for the MG2 motor since the MG2 controller is a hardware controller, MicroAutoBox. The MG2 motor model communicates with MicroAutobox via DS 5202 board. Analog outputs to the MicroAutoBox include three-phase current, a MG2 RPM and MG2 torque request. The resultant torque applied by PMSM motor needs to be perpendicular to mechanical rotor position to get maximum efficiency of motor. The HIL simulator uses an Angular Processing Unit (APU) to capture the angle of rotor position.

\subsection{Environment}

The environment subsystem has all the maneuverability and the driver signals. Maneuverability sends the signal of vehicle reference velocity. The driver signals are APP, BPP, and gear lever selection signals. A PI controller with feed forward and feedback position is used to control the APP and BPP positions. 


\section{HI L SI MULATI ON AND RESULT DI SCUSSI ON}

\section{1. dSPACE HI L Simulator}

Any design of power-split configuration and its control strategy needs to be tested. It's better if the tests are before manufacturing of components. It will allow and reduce the time frame for optimum design. To get the test results close to actual results after manufacturing, real world testing is of great importance. Once a dynamic model of a vehicle is tested in software, the plant model and its control algorithms of various systems and subsystems can be tested with latest edition of simulator from dSPACE. The main plant model is built for dSPACE ECOLine simulator and Motors is controlled with MicroAutobox II for this testing of vehicle. The ECOLine simulator has a DS1006 quad core board. The simulator has 3 ECUs with various configuration points given in document [17]. The simulator contains the digital signal conditioners, signal processors, various sensor and actuator interfaces. DS5202 board is being used for communication between simulator and MicroAutobox. The MicroAutobox contains two boards, 1511 and 1512 board and DS1552 piggyback board. The box acts as a motor controller. The 1512 board contains all the ADC and Hall Effect sensor interfaces but doesn't have any Controller Area Network (CAN) interfaces. The 1511 contains CAN interface as well as serial interface for the communication with other ECUs. Basic functionality of the simulator is to act as a vehicle plant while connected to the hardware ECU which controls plant. If hardware ECUs are not present, softECUs can also be implemented in the simulator with vehicle plant model. Once model is completed and debugged, the binary simulation code can be easily generated by auto-code generation software and downloaded to simulation board. If hardware ECUs are presented in the simulation system, the code for these controllers can be flashed to corresponding controllers so that the simulation can be run with hardware-in-the-loop

The model calibration is done in ControlDesk software provided by dSPACE Inc. Once the model is built in the Simulink environment, it is flashed onto simulator board. ControlDesk uses variables from *.sdf file which is created while building the model. The ControlDesk allows calibrating variables in real-time using different instruments. 
The software is extremely helpful for real-time calibration of variables such as gain values of PI controllers.

\subsection{HI L Simulation Setup}

HIL simulation setup was done by connecting the ECOLine simulator and MicroAutobox. The details of connection are listed in the Table 4. The simulation computer was connected to the HIL simulator directly while the MicroAutobox was connected using an Ethernet cable. When registering the simulator platform and MicroAutobox platform, the simulator can be detected without IP address while the MicroAutobox needs to be inserted with IP of 141.219.24.56. Figure 5.1 shows the HIL simulation setup.

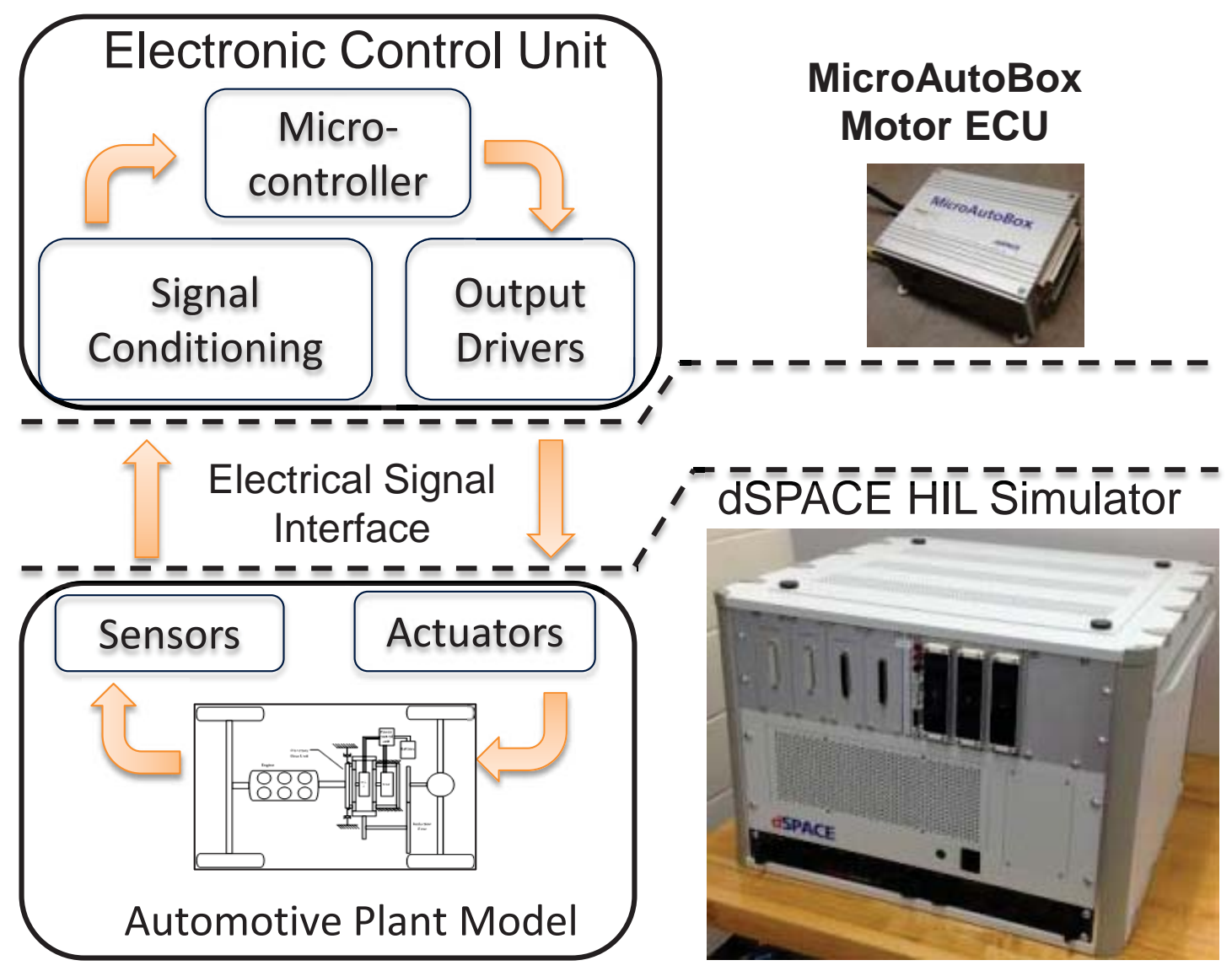

Figure 5.1: HIL simulation set-up 
Table 4 : The connections between HIL simulator and MicroAutoBox

\begin{tabular}{|c|c|c|c|}
\hline $\begin{array}{l}\text { Sr. } \\
\text { No. }\end{array}$ & $\begin{array}{l}\text { DS5202 EMH } \\
\text { Simulator pins }\end{array}$ & MicroAutobox II pins & Signal \\
\hline 1 & $\begin{array}{l}\text { 37-pin Female Sub-D } \\
\text { Connector P1: Pin20 }\end{array}$ & Hall 1A D3 & Rotor position \\
\hline 2 & $\begin{array}{l}\text { 37-pin Female Sub-D } \\
\text { Connector P1: Pin21 }\end{array}$ & Hall 1A E6 & Rotor position \\
\hline 3 & $\begin{array}{l}\text { 37-pin Female Sub-D } \\
\text { Connector P1: Pin22 }\end{array}$ & Hall 1B D4 & Rotor position \\
\hline 4 & $\begin{array}{l}\text { 37-pin Female Sub-D } \\
\text { Connector P1: Pin23 }\end{array}$ & Hall 1B D5 & Rotor position \\
\hline 5 & $\begin{array}{l}\text { 37-pin Female Sub-D } \\
\text { Connector P1: Pin24 }\end{array}$ & Hall Z E4 & Rotor position \\
\hline 6 & $\begin{array}{l}\text { 37-pin Female Sub-D } \\
\text { Connector P1: Pin25 }\end{array}$ & Hall Z E5 & Rotor position \\
\hline 7 & $\begin{array}{l}\text { 50-pin Female Sub-D } \\
\text { Connector P2: Pin41 }\end{array}$ & ADC Input-pin & Three Phase current \\
\hline 8 & $\begin{array}{l}\text { 50-pin Female Sub-D } \\
\text { Connector P2: Pin } 25\end{array}$ & ADC Input-pin & Three Phase current \\
\hline 9 & $\begin{array}{l}\text { 50-pin Female Sub-D } \\
\text { Connector P2: Pin9 }\end{array}$ & ADC Input-pin & Three Phase current \\
\hline 10 & $\begin{array}{l}\text { 50-pin Female Sub-D } \\
\text { Connector P2: Pin42 }\end{array}$ & ADC Input-pin & Three Phase current \\
\hline 11 & $\begin{array}{l}\text { 50-pin Female Sub-D } \\
\text { Connector P2: Pin10 }\end{array}$ & ADC Input-pin & Voltage signal \\
\hline 12 & $\begin{array}{l}\text { 50-pin Female Sub-D } \\
\text { Connector P2: Pin43 }\end{array}$ & ADC Input-pin & Voltage signal \\
\hline 13 & $\begin{array}{l}\text { 50-pin Female Sub-D } \\
\text { Connector P2: Pin27 }\end{array}$ & ADC Input-pin & Three Phase current \\
\hline 14 & $\begin{array}{l}\text { 50-pin Female Sub-D } \\
\text { Connector P2: Pin11 }\end{array}$ & ADC Input-pin & Three Phase current \\
\hline 15 & $\begin{array}{l}\text { 50-pin Female Sub-D } \\
\text { Connector P2: Pin28 }\end{array}$ & ADC Input-pin & Torque request signal \\
\hline 16 & $\begin{array}{l}\text { 50-pin Female Sub-D } \\
\text { Connector P2: Pin } 12\end{array}$ & ADC Input-pin & Torque request signal \\
\hline 17 & $\begin{array}{l}\text { 50-pin Female Sub-D } \\
\text { Connector P2: Pin5 }\end{array}$ & $\begin{array}{l}\text { Resolver Excitation- } \\
\text { a4 }\end{array}$ & $\begin{array}{l}\text { analog position sensor } \\
\text { signal }\end{array}$ \\
\hline 18 & $\begin{array}{l}\text { 50-pin Female Sub-D } \\
\text { Connector P2: Pin38 }\end{array}$ & $\begin{array}{l}\text { Resolver Excitation- } \\
\text { b6 }\end{array}$ & $\begin{array}{l}\text { analog position sensor } \\
\text { signal }\end{array}$ \\
\hline 19 & $\begin{array}{l}\text { 50-pin Female Sub-D } \\
\text { Connector P3: Pin18 }\end{array}$ & Resolver Sine a5 & $\begin{array}{l}\text { analog position sensor } \\
\text { signal }\end{array}$ \\
\hline 20 & $\begin{array}{l}\text { 50-pin Female Sub-D } \\
\text { Connector P3: Pin } 2\end{array}$ & Resolver Sine a6 & $\begin{array}{l}\text { analog position sensor } \\
\text { signal }\end{array}$ \\
\hline
\end{tabular}




\begin{tabular}{|c|c|c|c|}
\hline 21 & $\begin{array}{l}\text { 50-pin Female Sub-D } \\
\text { Connector P3: Pin35 }\end{array}$ & Resolver Cosine c6 & $\begin{array}{l}\text { analog position sensor } \\
\text { signal }\end{array}$ \\
\hline 22 & $\begin{array}{l}\text { 50-pin Female Sub-D } \\
\text { Connector P3: Pin19 }\end{array}$ & Resolver Cosine b5 & $\begin{array}{l}\text { analog position sensor } \\
\text { signal }\end{array}$ \\
\hline 23 & $\begin{array}{l}\text { 50-pin Female Sub-D } \\
\text { Connector P3: Pin27 }\end{array}$ & Digital In 7 T5 & \multirow{3}{*}{$\begin{array}{l}\text { Incremental Encoder Signal } \\
\text { Incremental Encoder Signal } \\
\text { Duty Cycle }\end{array}$} \\
\hline 24 & $\begin{array}{l}\text { 50-pin Female Sub-D } \\
\text { Connector P3: Pin14 }\end{array}$ & Digital In 8 T6 & \\
\hline 25 & $\begin{array}{l}\text { 37-pin Female Sub-D } \\
\text { Connector P4: Pin20 }\end{array}$ & PWM Input R3 & \\
\hline 26 & $\begin{array}{l}\text { 37-pin Female Sub-D } \\
\text { Connector P4: Pin21 }\end{array}$ & PWM Input R5 & Duty Cycle \\
\hline 27 & $\begin{array}{l}\text { 37-pin Female Sub-D } \\
\text { Connector P4: Pin22 }\end{array}$ & PWM Input S5 & Duty Cycle \\
\hline 28 & $\begin{array}{l}\text { 37-pin Female Sub-D } \\
\text { Connector P4: Pin23 }\end{array}$ & PWM Input R6 & Duty Cycle \\
\hline 29 & $\begin{array}{l}\text { 37-pin Female Sub-D } \\
\text { Connector P4: Pin24 }\end{array}$ & PWM Input R4 & Duty Cycle \\
\hline 30 & $\begin{array}{l}\text { 37-pin Female Sub-D } \\
\text { Connector P4: Pin25 }\end{array}$ & PWM Input S4 & Duty Cycle \\
\hline
\end{tabular}

\subsection{HI L Simulation Results and Discussion}

This report is focused on testing of the modeled power-split device and its performance in a vehicle environment using HIL simulation. The power-split model was integrated into vehicle model in Simulink environment. The compiled vehicle model was loaded onto the simulator processor board while the control model of MG2 was loaded onto to the MicroAutobox. Once the models were downloaded, the simulation was performed with ControlDesk software for real-time calibration. The simulation was conducted for an Urban Dynamometer Drive Schedule (UDDS) drive cycle over a period of 1400 seconds. 
Figure 5.2 shows the comparison between reference UDDS drive cycle and HIL simulation results of power-split vehicle. The reference drive cycle is built into the environment level of vehicle model. The drive cycle is followed precisely at most time. The simulation output exceeds reference vehicle speed only for a short period of time starting at $480 \mathrm{sec}$ due to rule-based control actions of hybrid mode controller. The torque provided by engine is in excess to torque request to keep engine running and charge the battery above $60 \%$. The maximum error of vehicle speed is $1 \%$ in EV mode and $4 \%$ in hybrid mode except a short period of time starting at $480 \mathrm{sec}$, within which an error of $10 \%$ is observed. The simulation result in Figure 5.2 gives a good base to conclude that the vehicle model is working properly with developed power-split device model and rule-based control strategy.

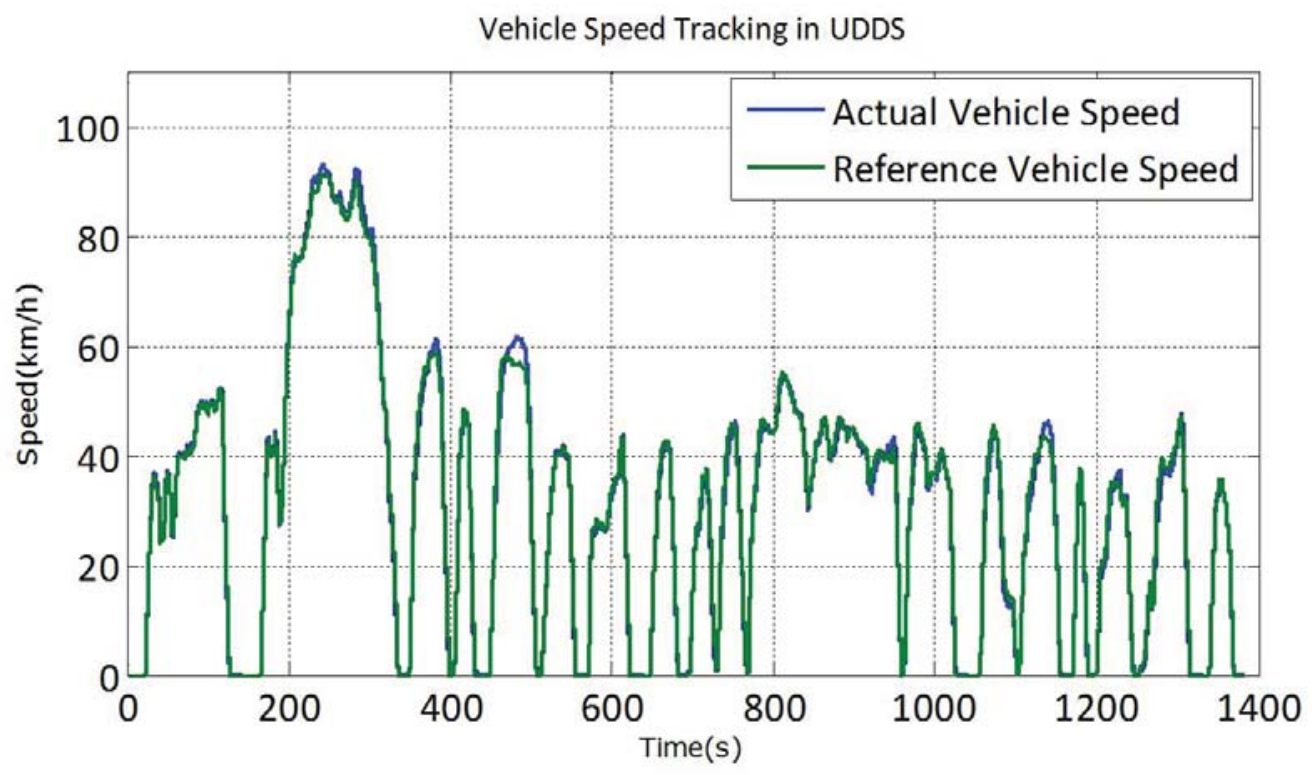

Figure 5.2 : Vehicle Speed tracking in UDDS 
Figure 5.3 shows the engine torque request in hybrid mode and the actual amount generated by the engine. Engine output torque follows closely in most cases except at highly spiked request time instances as shown in magnified figure. In these cases, engine is not able to generate enough output torque within such a short time period. One example is when $\mathrm{t}=\mathbf{2 0 5}$ seconds. In other cases, engine produces and follows torque precisely as requested. Throughout the drive cycle, engine is in power mode only for charge sustaining and charging the battery. Engine is turned off for charge depletion in electric only mode.

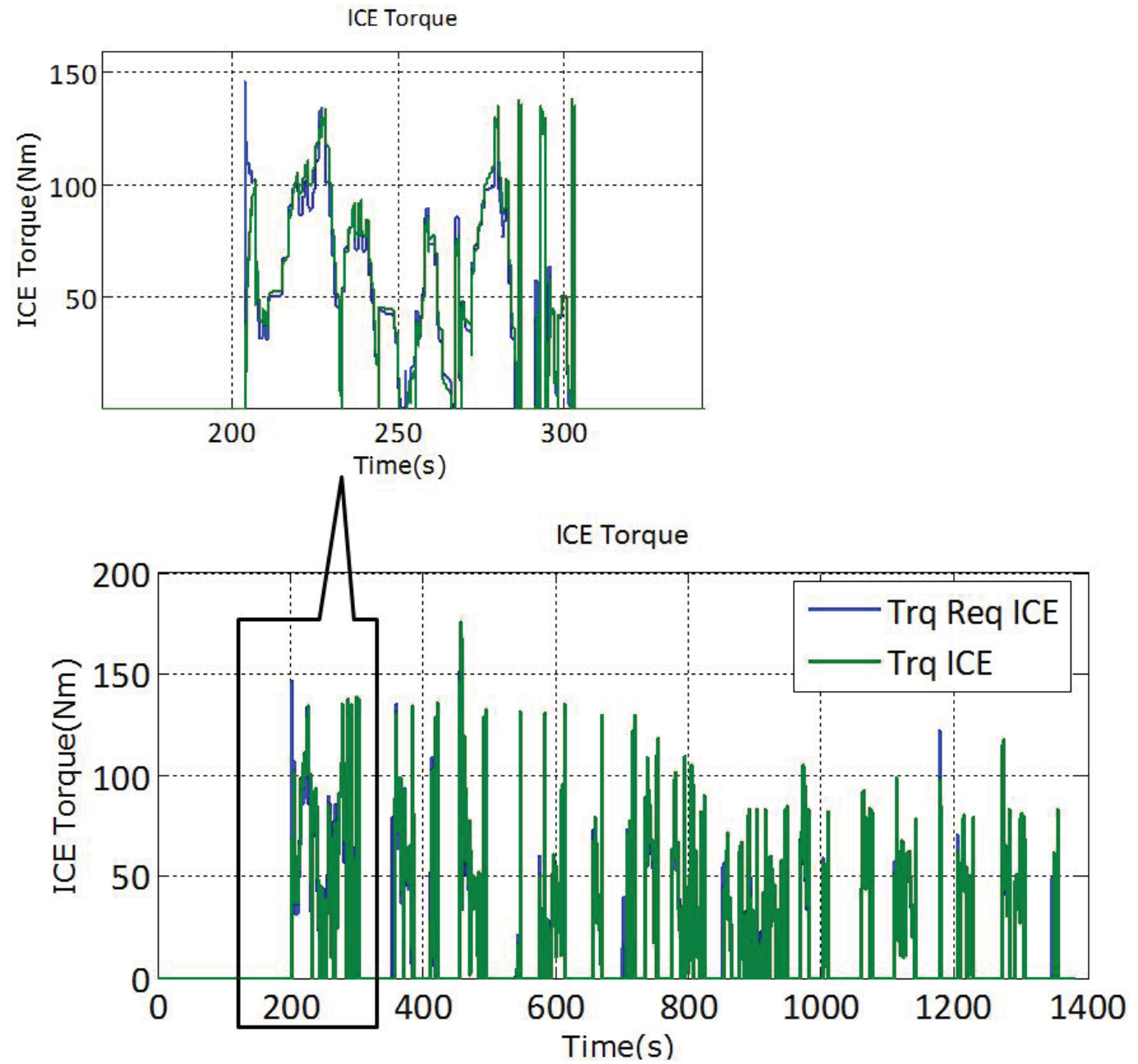

Figure 5.3: Comparison of requested ICE torque and generated ICE torque 
Figure 5.4 shows the SOC of the battery. As per the control strategy, the primary function of engine power mode is to increase SOC level to $70 \%$ limit. The engine starts to charge battery as soon as SOC falls below 60\%. Figure 5.2 shows that the velocity profiles are almost repetitive after 350 seconds. Hence, the engine charges the battery at peak velocity profiles while regenerative strategy shuts the engine off. The SOC drops in electric only mode significantly to provide necessary vehicle starting torque. After that, the SOC is maintained around $60 \%$.

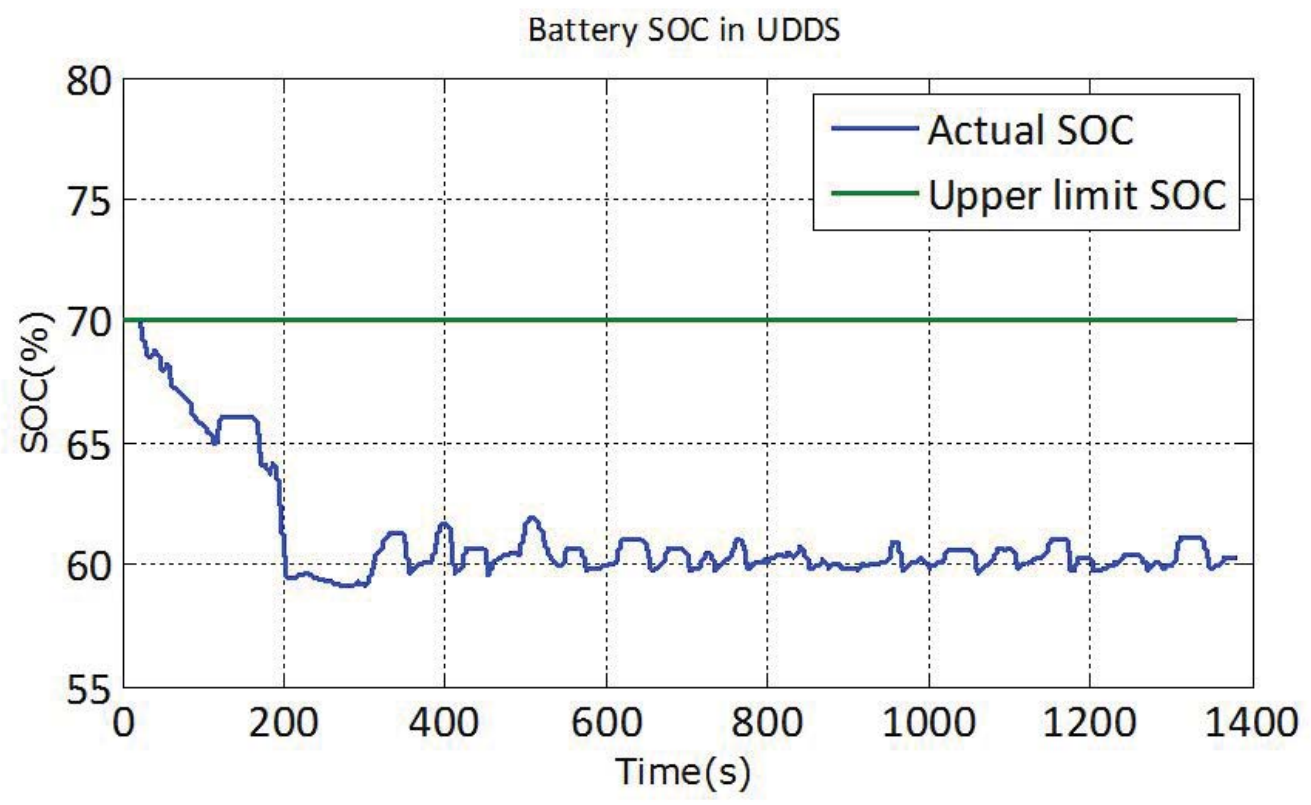

Figure 5.4: Comparison of battery SOC with SOC upper limit 
Figure 5.5 shows the RPM of MG2, primary driving motor. The motor rotates in counter clockwise direction and the wheels are in clockwise direction. As the wheels moving forward are positive, motor direction has to be negative. The motor RPM is recorded in simulation for EV and hybrid mode. The MG2 RPM is directly connected to the wheel RPM by a gear ratio of 2.6 reduction and 2.2 differential. As a result, the MG2 has the same profile as that of vehicle speed but in opposite direction.

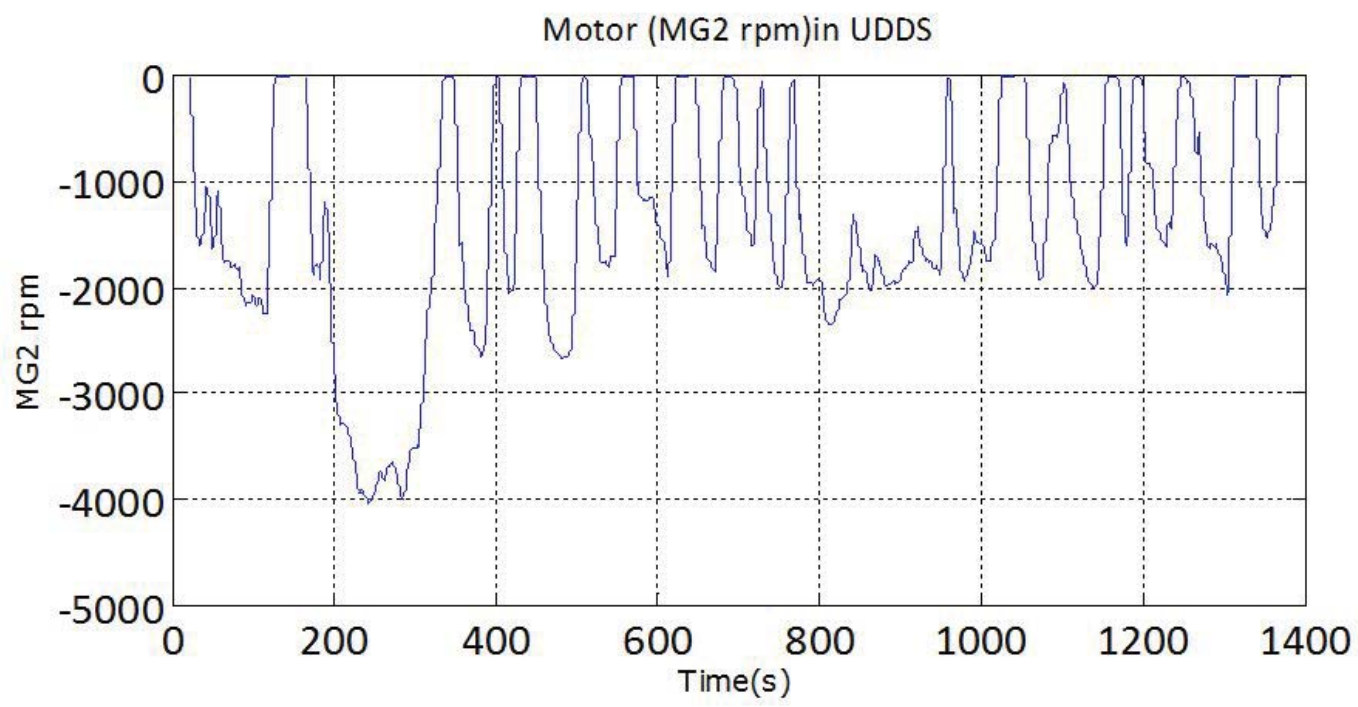

Figure 5.5: The RPM of primary motor, MG2 
Figure 5.6 shows the RPM of the generator. The generator acts as a motor in EV mode and as a generator in Hybrid mode. In EV mode, engine can be off or idling. Once the clutch is released, MG1 acts as a starter motor along with MG2 to start the engine. As the RPM of engine in starting and idling mode are limited to 800RPM, MG1 has to act quickly in clockwise direction to help ring in starting the engine. That's why there are spikes in MG1 towards positive direction. In EV mode and regenerative braking, MG1 and MG2 gear ratios are similar (2.6 and 2.63). It can be seen that velocity profile of MG1 and MG2 are same while braking.

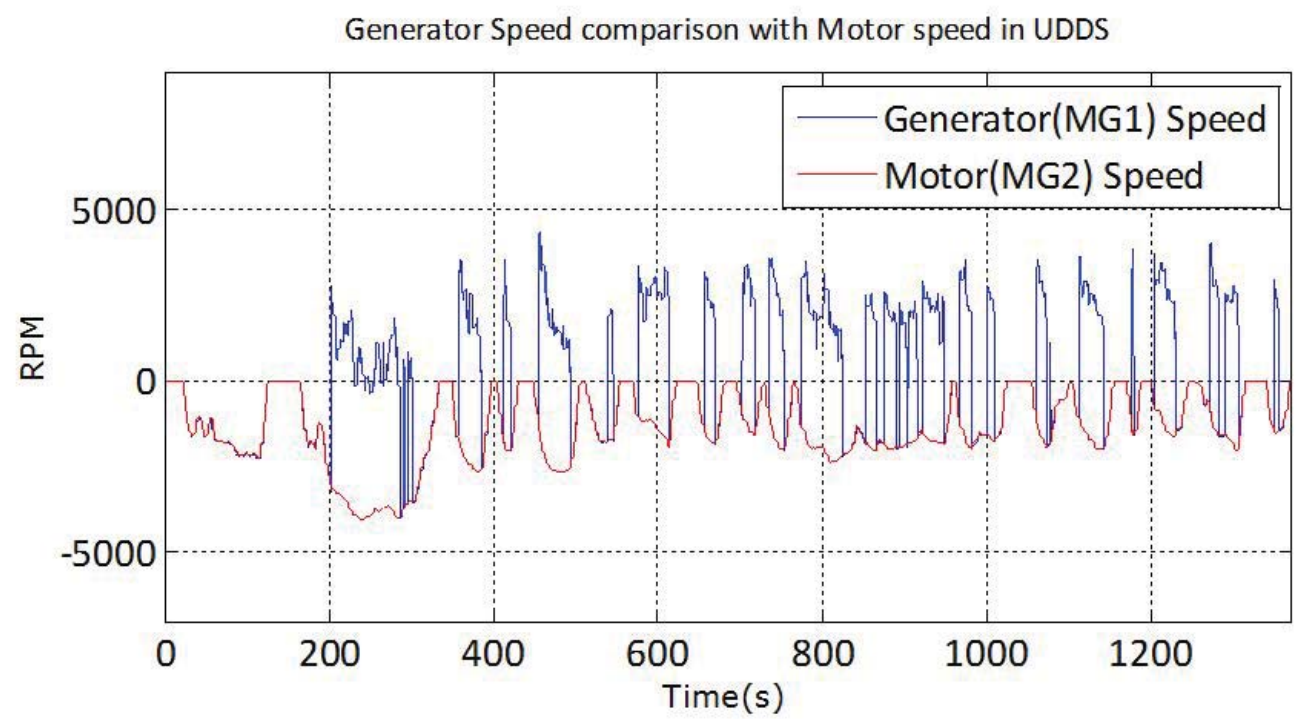

Figure 5.6: The RPM of secondary motor MG1 
Figure 5.7 shows different ICE modes attended in comparison with vehicle velocity. The ICE mode $=0$ is engine off, ICE mode $=1$ is engine idling, ICE mode $=2$ is engine power mode. The rule-based control strategy for ICE mode selection is governed by SOC percent. When the SOC drops below 60\%, the engine starts and it either operates in charge sustaining mode or in charging mode as per the torque request. As it is seen in Figure 5.4, SOC level is risen up to $62 \%$ by the end of 350 seconds. After 350 seconds, the drive cycle is almost repetitive. Hence, the engine starts at the start of each peak and stops when regenerative braking is applied.

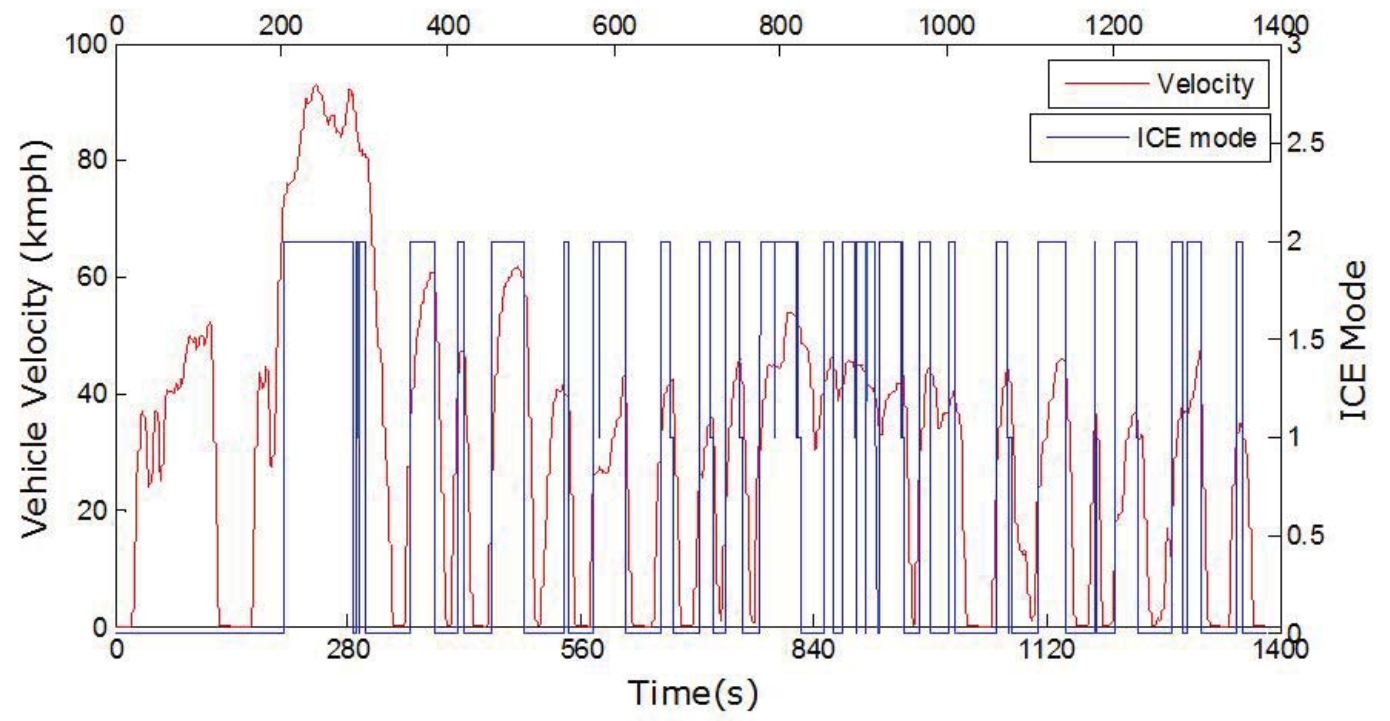

Figure 5.7: Comparison of ICE mode change with vehicle velocity 
Figure 5.8 shows the comparison between engine RPM and MG1 RPM. In hybrid mode, MG1 compensates engine RPM for given vehicle speed. The engine RPM is limited by the MG1 maximum speed of $8700 \mathrm{rpm}$. MG1 RPM is calculated by Eq.15 in hybrid mode. The RPM profile is close to engine profile with deviation of MG2 profile. The spikes seen are due to sudden change of MG1 speed from counter clockwise to clockwise to start the engine.

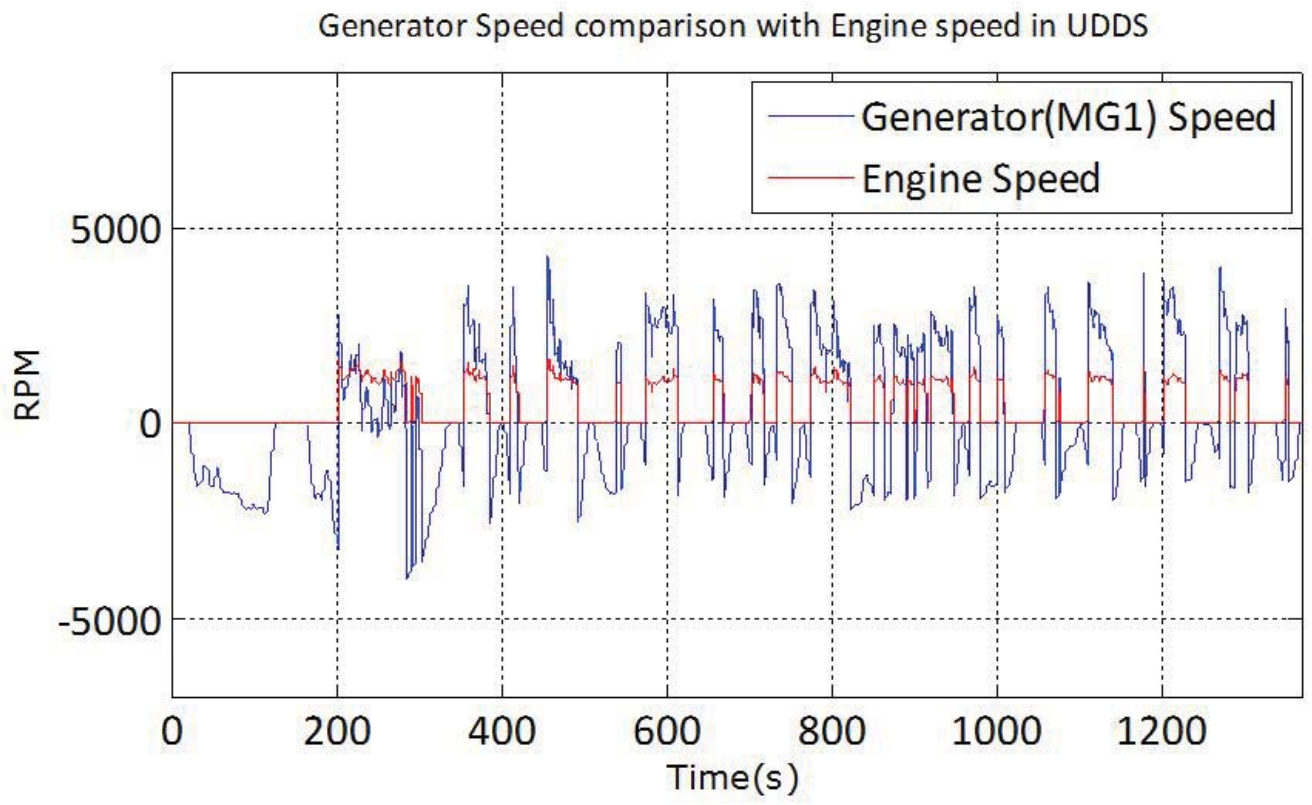

Figure 5.8: Generator RPM and engine RPM

Figure 5.9 shows the comparison of vehicle mode and ICE mode with rotational speeds of MG1, MG2, and engine. Vehicle has two modes: Electric only (EV) mode $=0$ and Hybrid mode $=1$. Engine has three modes: power mode (ICE mode=2), idling mode (ICE mode=1), and engine off mode (ICE mode=0). Vehicle mode changes to Hybrid mode only when the ICE is in power mode (ICE mode=2). The powertrain components follow the primary kinematic equation given in Eq. 15 in hybrid mode. The powertrain components connected directly to wheels via gear ratios. In electric only mode, motors follow vehicle velocity profile while engine rpm is 0 . The simulation result shows that the power-split device is successfully integrated into vehicle model. 


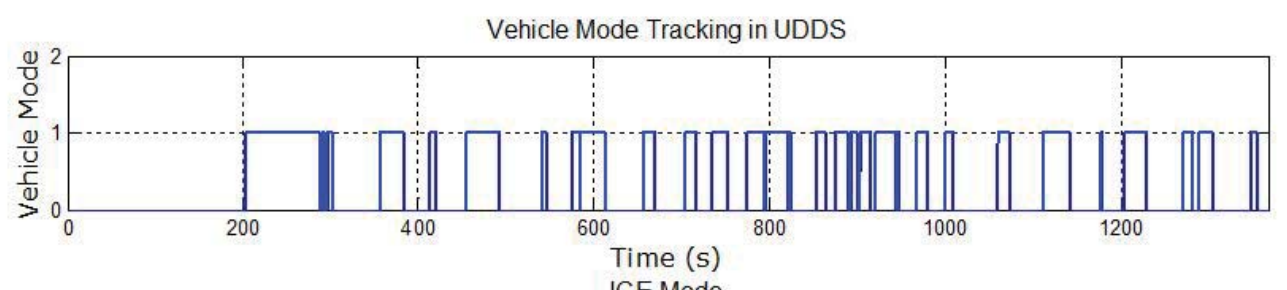

ICE Mode

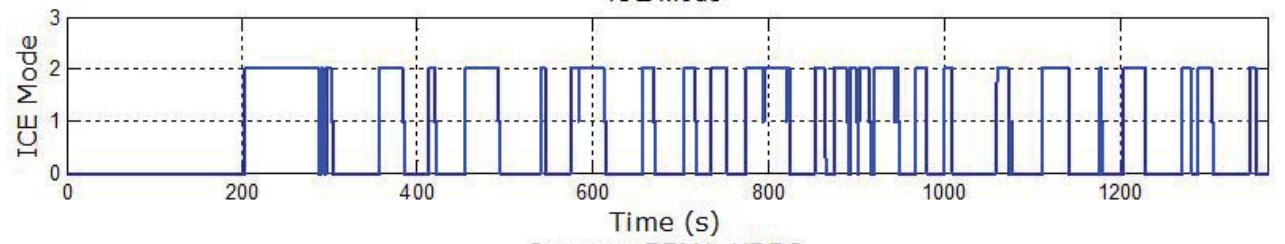

Generator RPM in UDDS

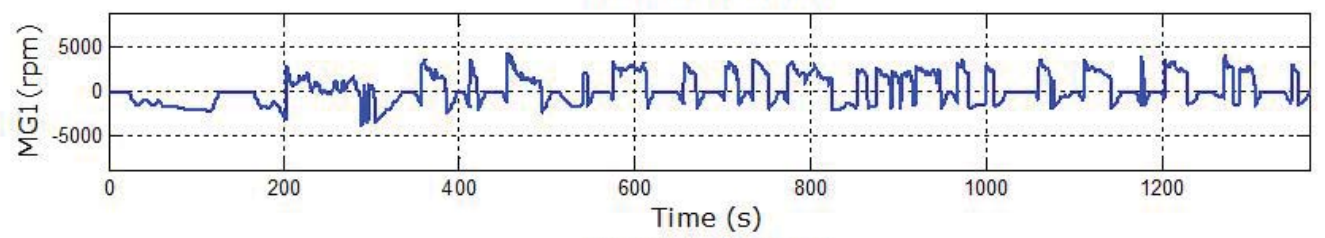

Engine RPM in UDDS

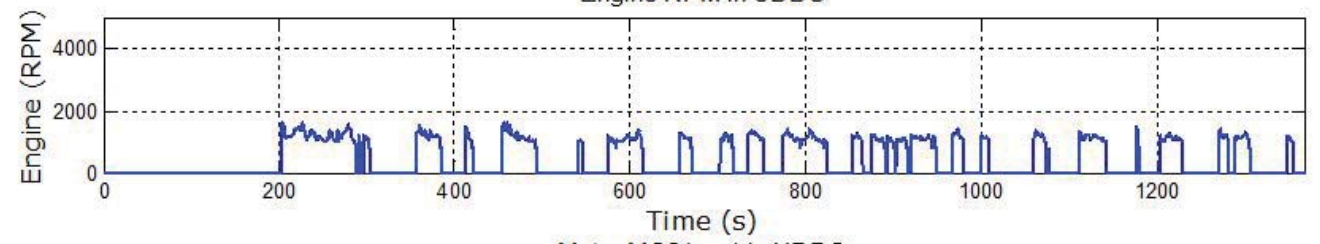

Motor MG2(rpm) in UDDS

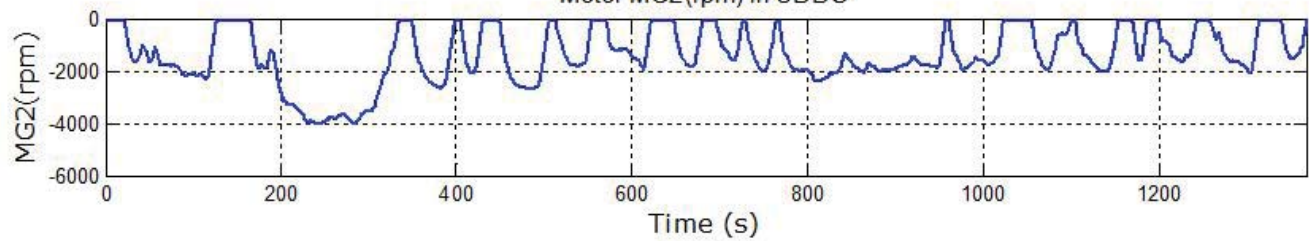

Figure 5.9: Vehicle and ICE mode comparison with powertrain components 
Figure 5.10 shows the engine operating points, in red dots, with respect to Brake Specific Fuel Consumption (BSFC) map. The control strategy for engine operation is based on power request and optimum power-speed curve. Low power request and high engine torque capacity makes the engine operation at lower side of torque curve and not utilizing engine to its optimum capacity. Higher fuel efficiency of the vehicle can be achieved by increasing the power-split ratio on engine side so that engine is operated at high torque and rpm values.

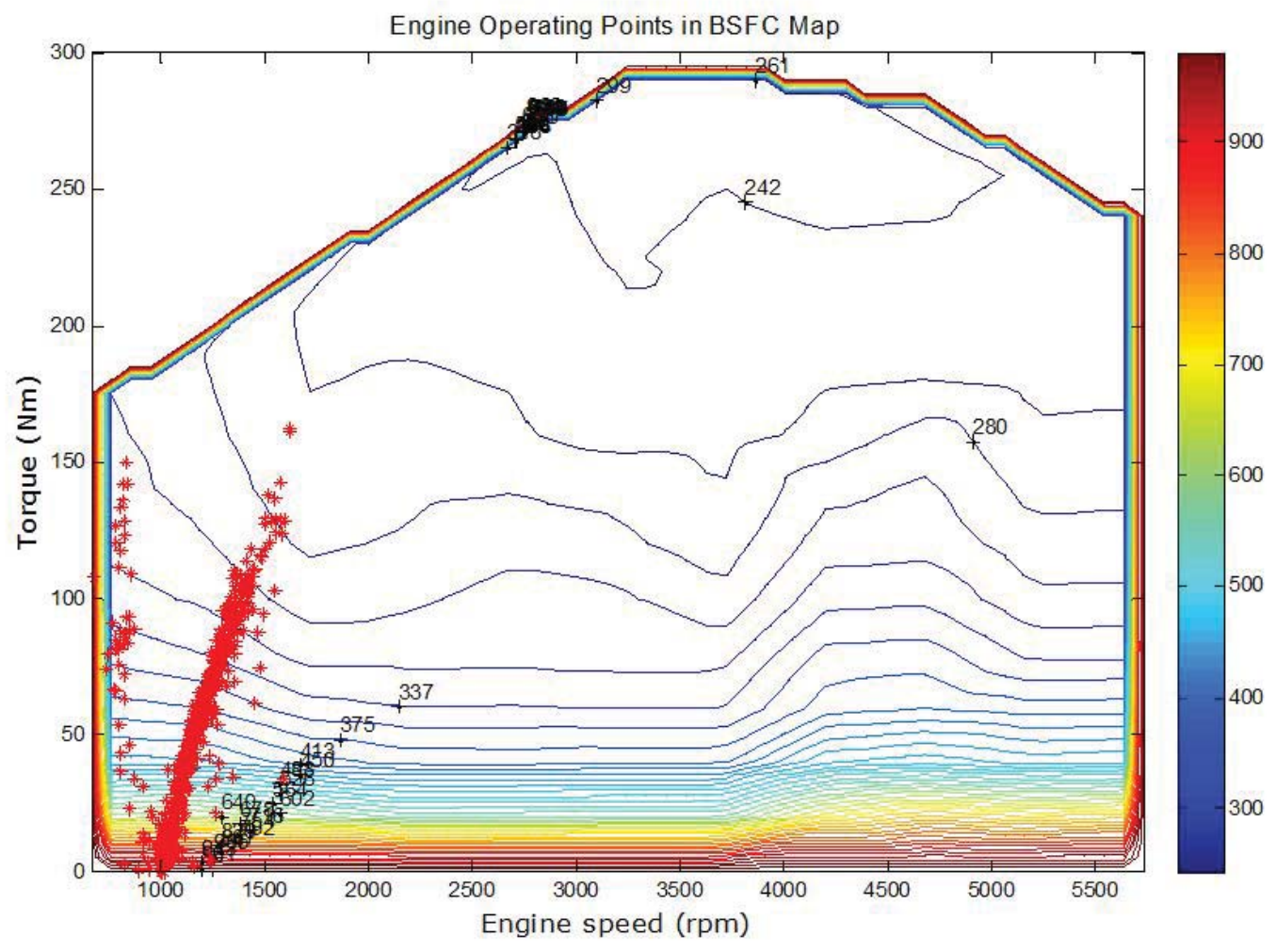

Figure 5.10: Engine operating points in BSFC map of 2.9 liter engine 
Figure 5.11 shows the comparison of MG2 operating points on efficiency map. The MG2 operating points are in black dots. MG2 operates in orange to yellow region giving efficiency close to $85 \%$. Most of the torque points are low as motor capacity is high and torque demand is comparatively low.

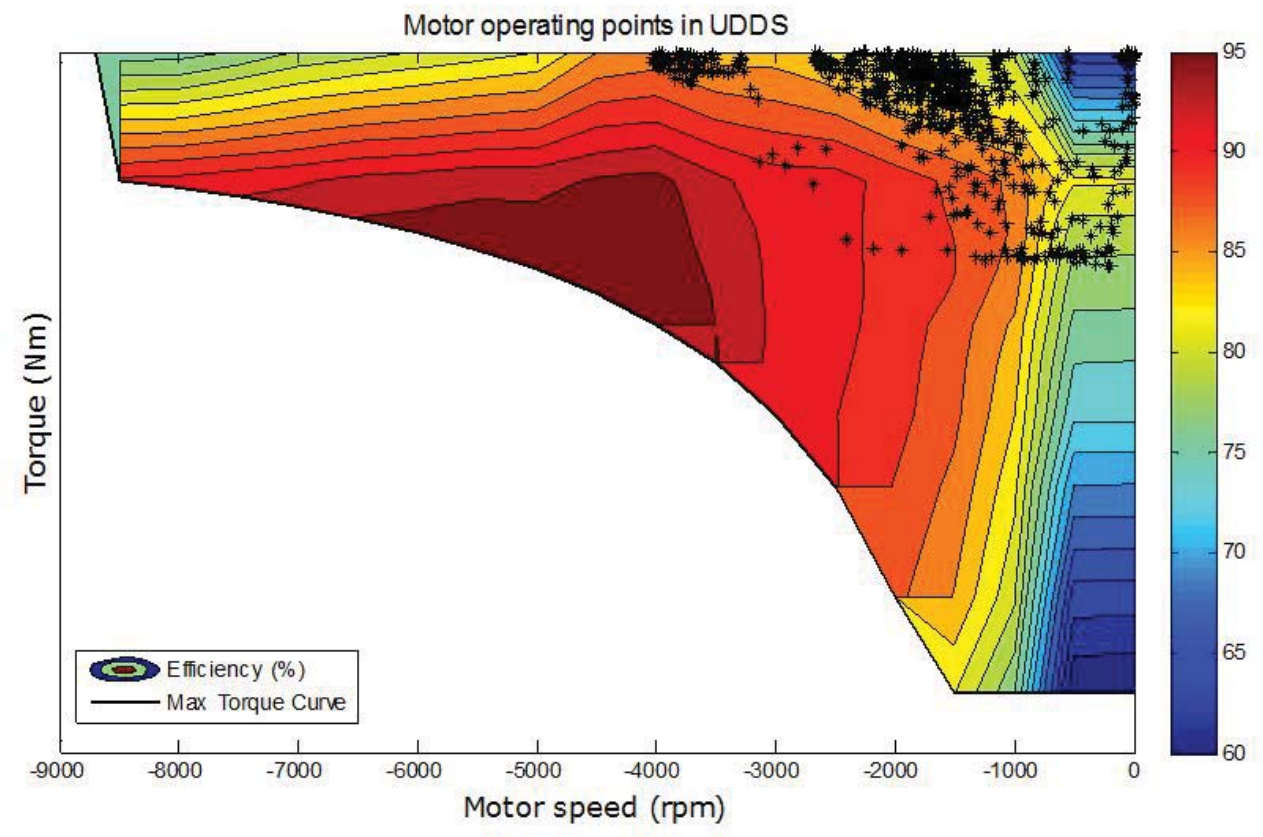

Figure 5.11: MG2 motor operating points on motor efficiency map 


\section{CONCLUSIONS AND FUTURE WORK}

The power-split vehicle developed in Simulink environment for HIL simulation has been implemented successfully. The power-split device allows independent engine RPM from vehicle speed helping in engine level optimization of vehicle. The dynamic model of third generation of THS (hybrid synergy drive) was developed and validated using HIL simulation. An added clutch to engine carrier allows vehicle operating in two modes. The electric vehicle mode is useful in initial acceleration and high torque requirement. In hybrid mode, the engine performance can be improved with variation in MG1 motor/generator and better control strategy. The HIL simulation was validated with ControlDesk software and the results were reported.

The recommended future work includes following:

- The created model is input split configuration for hybrid synergy drive. Other configurations of power-split can be modeled and tested.

- A better control strategy for clutched version of hybrid synergy drive can help to improve the efficiency of the vehicle.

- Change in motor and engine rating can be done to optimize the vehicle performance.

- An optimum gear ratio can be implemented to optimize the vehicle performance.

- A better clutch model is necessary to incorporate the dynamics of the clutch into the power-split model. 


\section{REFERENCES}

1. Ehsani, M., Modern electric, hybrid electric, and fuel cell vehicles fundamentals, theory, and design2010: Boca Raton : CRC Press, 2010.

2. Tate, E.D., M.O. Harpster, and P.J. Savagian, The Electrification of the Automobile: From Conventional Hybrid, to Plug-in Hybrids, to ExtendedRange Electric Vehicles. SAE Int. J. Passeng. Cars - Electron. Electr. Syst., 2008. 1(1): p. 156-166.

3. Chen, D.B., MEEM5750 Distributed Embedded Control System, 2012, Michigan Technological University.

4. Meisel, J., An Analytic Foundation for the Toyota Prius THS-II Powertrain with a Comparison to a Strong Parallel Hybrid-Electric Powertrain, 2006, SAE International.

5. Aimin, D. and C. Hongwei. An analytic foundation for the Two-mode hybrid transmission with a comparison to other hybrid vehicle power split transmissions. in Transportation, Mechanical, and Electrical Engineering (TMEE), 2011 International Conference on. 2011.

6. Xiaowu, Z., et al., Prius+and Volt-: Configuration Analysis of Power-Split Hybrid Vehicles With a Single Planetary Gear. Vehicular Technology, IEEE Transactions on, 2012. 61(8): p. 3544-3552.

7. Liu, J., Modeling, Configuration and Control Optimization of Power-split Hybrid Vehicles, in Mechanical Engineering2007, University of Michigan.

8. Poramapojana, P., Predictive control of hybrid vehicle powertrain for intelligent energy management, 2012, Michigan Technological University. p. xvii, $91 \mathrm{p}$.

9. Jinming, L. and P. Huei, Modeling and Control of a Power-Split Hybrid Vehicle. Control Systems Technology, IEEE Transactions on, 2008. 16(6): p. 12421251.

10. Musardo, C., G. Rizzoni, and B. Staccia. A-ECMS: An Adaptive Algorithm for Hybrid Electric Vehicle Energy Management. in Decision and Control, 2005 and 2005 European Control Conference. CDC-ECC '05. 44th IEEE Conference on. 2005.

11. Namwook, K., C. Sukwon, and P. Huei, Optimal Control of Hybrid Electric Vehicles Based on Pontryagin's Minimum Principle. Control Systems Technology, IEEE Transactions on, 2011. 19(5): p. 1279-1287.

12. Mizuno, Y., et al., Development of New Hybrid Transmission for CompactClass Vehicles. SAE Int. J. Engines, 2009. 2(1): p. 742-749.

13. Willis, R., Principles of Mechanism1841, Cambridge University Press.

14. Olszewski, M., EVALUATION OF THE 2010 TOYOTA PRIUS HYBRID SYNERGY DRIVE SYSTEM. FY2011. ORNL/ TM-2010/ 253.

15. Kim, N., A. Rousseau, and E. Rask, Autonomie Model Validation with Test Data for 2010 Toyota Prius, 2012, SAE International.

16. Inc., d., ASM Electric Component Reference, 2011: dSPACE GmbH, Rathenaustraße 26, 33102 Paderborn, Germany.

17. Inc., d., dSPACE Simulator EcoLine Hardware Installation and Configuration, 2010: dSPACE GmbH, Rathenaustraße 26, 33102 Paderborn, Germany. 